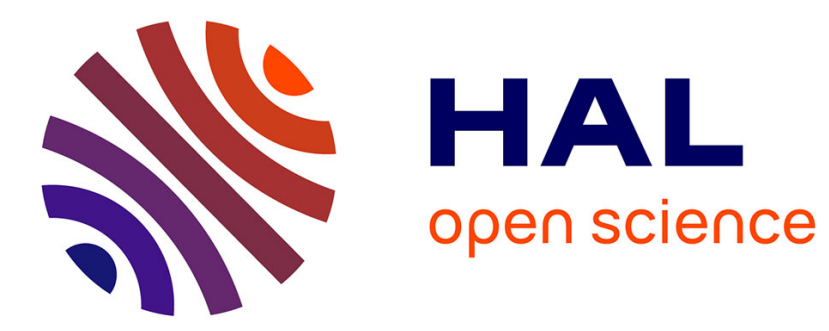

\title{
Environmental interactions during the extreme rain event associated with ex-tropical cyclone Oswald (2013)
}

Marie-Dominique Leroux, Mai C Nguyen-Hankinson, Noel E Davidson, Jeffrey Callaghan, Kevin Tory, Alan Wain, Xinmei Huang

\section{- To cite this version:}

Marie-Dominique Leroux, Mai C Nguyen-Hankinson, Noel E Davidson, Jeffrey Callaghan, Kevin Tory, et al.. Environmental interactions during the extreme rain event associated with ex-tropical cyclone Oswald (2013). Journal of Southern Hemisphere Earth Systems Science, 2019, 69 (1), pp.216. 10.1071/ES19016 . hal-03053372

\section{HAL Id: hal-03053372 https://hal.science/hal-03053372}

Submitted on 11 Dec 2020

HAL is a multi-disciplinary open access archive for the deposit and dissemination of scientific research documents, whether they are published or not. The documents may come from teaching and research institutions in France or abroad, or from public or private research centers.
L'archive ouverte pluridisciplinaire HAL, est destinée au dépôt et à la diffusion de documents scientifiques de niveau recherche, publiés ou non, émanant des établissements d'enseignement et de recherche français ou étrangers, des laboratoires publics ou privés. 


\title{
Environmental interactions during the extreme rain event associated with ex-tropical cyclone Oswald (2013)
}

\author{
Marie-Dominique Leroux ${ }^{\mathrm{A}, \mathrm{G}}$, Mai C. Nguyen-Hankinson ${ }^{\mathrm{B}}$, Noel E. Davidson ${ }^{\mathrm{C}}$, \\ Jeffrey Callaghan ${ }^{\mathrm{D}}$, Kevin Tory ${ }^{\mathrm{E}}$, Alan Wain ${ }^{\mathrm{F}}$ and Xinmei Huang ${ }^{\mathrm{F}}$ \\ A Laboratoire de l'Atmosphère et des Cyclones (Unité Mixte 8105 CNRS/Météo-France/Université \\ de La Réunion), 50 bvd du chaudron, 97490 Saint-Denis, de la Réunion, France. \\ ${ }^{B}$ Department of Mathematical Sciences, Monash University, Melbourne, Vic., Australia. \\ ${ }^{\mathrm{C}}$ Centre for Australian Weather and Climate Research, A partnership between the Australian \\ Bureau of Meteorology and CSIRO, Melbourne, Vic., Australia. \\ D Formerly Bureau of Meteorology, Queensland Regional Forecasting Centre, Brisbane, Qld., \\ Australia. \\ ${ }^{\mathrm{E}}$ Science and Innovation Group, Australian Bureau of Meteorology, Melbourne, Vic., Australia. \\ ${ }^{\mathrm{F}}$ Bureau National Operations Centre, Bureau of Meteorology, Melbourne, Vic., Australia. \\ ${ }^{\mathrm{G}}$ Corresponding author. Email: mariedominique.leroux@gmail.com
}

\begin{abstract}
Tropical cyclone (TC) Oswald made landfall over north-east Australia as a minimal or Category 1 TC on the Australian scale on 21 January 2013. As it moved southward, it intensified over land and produced extreme rainfall for nearly 7 days. Tornadoes were reported and confirmed. Tragically, seven people died and insurance estimates were $\sim \$ 1$ billion. It is demonstrated that the event was associated with an interaction between the ex-Oswald circulation and an amplifying Rossby wave, which propagated north-eastward from high latitudes. Diagnoses showed that as the wave amplified and broke, a potential vorticity (PV) anomaly (PVA) extended to mid-levels, moved equatorward, merged with or axisymmetrised the ex-Oswald circulation through mid-levels. Backward trajectories from locations regularly scattered within the mid-level circulation illustrated that the storm transitioned from an isolated vortex into a circulation which was strongly influenced by its environment for at least 5 days. During this interaction, PV was advected from the environment towards the storm through mid-levels. The heavy rain coincided with the commencement and maintenance of this PV injection. The PV injection is quantified and shown to be consistent with PV advection by the mean radial flow. In addition, eddy angular momentum convergence in the mid- to upper levels coincided with an intensification of the circulation through this region. This was first related to outward transport of anticyclonic momentum by the asymmetric outflow at upper levels, followed by inward transport of cyclonic momentum by the asymmetric inflow. It is shown that the environmental interaction had an impact on vortex structure changes, rainfall and tornado development. We propose that the environmental processes influenced the ascent within the storm (1) via differential vorticity advection and baroclinic forcing, as the mid- to upper level PVA approached the circulation and (2) by low- to mid-level warm air advection.
\end{abstract}

Received 26 April 2019, accepted 23 October 2019, published online 11 June 2020

\section{Introduction}

At landfall, tropical cyclones (TCs) pose significant forecast problems because of the potential devastation to life and property from strong winds and heavy rain (e.g. Chen 2012). The task of forecasting the distribution and local intensity of rainfall, particularly heavy rain, is very challenging. Although most of the numerical forecast guidance for the event described here was of good quality, it is still very important to analyse the event to see if we can understand the physical mechanisms that produced such a high-impact rain event.

After TCs make landfall, they normally weaken and rainfall correspondingly decreases. For the case analysed here, this did not happen and in fact the storm strengthened after it made landfall and as it moved southwards. Other studies in the literature presented cases of TCs reintensifying over land, especially over northern Australia (e.g. Emanuel et al. 2008; Evans et al. 2011). Smith et al. (2015) presented a vorticity perspective of the genesis of TC Oswald over the Gulf of Carpentaria. They indicated that the storm developed on a monsoon shear line and that intensification continued as the low performed a loop over land from 18 to 20 January. They showed that moisture levels were high enough in the monsoon circulation to enable intensification over land following periodic bursts of convection near the circulation centre that concentrated absolute vorticity. 
When baroclinic potential energy is available from a westerly trough, the remnant circulation of a landfalling TC can revive and even produce enhanced rainfall (Dong et al. 2010; Bosart and Lackmann 1995). However, the precise nature of the 'interaction' does not seem to be well understood, and so one aim of the current study is to describe it more precisely. There are many studies on the 'interaction' between TCs and midlatitude baroclinic environments. Interestingly, they tend to focus on either the extratropical transition (ET, Evans et al. 2017) of TCs (e.g. Klein et al. 2000; Harr and Elsberry 2000; Jones et al. 2003; Ritchie and Elsberry 2003, 2007; Anwender et al. 2008; Keller et al. 2019; Pohorsky et al. 2019) or the antecedent rainfall well ahead of TCs (Cote 2007; Stohl et al. 2008; Srock and Bosart 2009; Galarneau et al. 2010; Lee and Choi 2010; Bosart et al. 2012; Baek et al. 2013; Moore et al. 2013). Oswald was not a well-defined ET event, since the circulation had made landfall and had weakened below TC intensity before any interaction took place. But it did have many characteristics of TCs undergoing ET. We show that it was clearly an extratropical interaction, and so it bears similarities with ET events. Rainfall mostly occurred following landfall and in association with the circulation itself, so it was not an antecedent rain event.

Leroux et al. (2016) give a comprehensive review of how upper level troughs or baroclinic forcing can alter the environment of TCs and have different impacts on storm intensity. Their numerical simulations of a realistic TC-trough interaction scenario suggest that the TC intensity modulation may depend on the maturity, and hence the vertical depth, of the storm. Vortices initially at tropical depression strength intensify much less than vortices at tropical storm strength or greater, the latter being able to benefit from the presence of a trough to reach their maximum potential intensity (Leroux et al. 2016). Observational analyses of TCs at tropical storm strength in the North Atlantic (Fischer et al. 2017) and western North Pacific systems (Wei et al. 2016) consistently indicate that, overall, upper level troughs promote TC intensification. For rapid intensification cases, the potential vorticity (PV) anomalies associated with the troughs are stronger and deeper compared to neutral intensification or slow intensification cases (Fischer et al. 2017). For the TC Dora (2007) case, Leroux et al. (2013) showed that PV injection at mid-levels from a mid-latitude cut-off low or PV coherent structure could help rapid intensification by increasing convection on the downshear side and sustaining the formation of an eyewall replacement cycle (PV budget analysis). They also noticed that the general $850-200 \mathrm{hPa}$ shear was not indicative of rapid intensification and that it would be more appropriate to use the $850-500 \mathrm{hPa}$ shear in some cases, which was confirmed in the recent study of Colomb et al. (2019).

The impact of troughs or mid-latitude baroclinic environments on TC events that did not intensify has not yet been documented in the literature. We want to investigate here if rain enhancement, instead of TC intensification, might be an outcome of such interactions for a TC-making landfall. Environmental interaction will be diagnosed via PV superposition, eddy angular momentum convergence and eddy PV fluxes. These processes and their associated variables are thoroughly described in the original study of Leroux et al. (2013) that investigates the main pathway to Dora's intensification under an upper level trough forcing: 'The wave activity of a trough can be viewed as large-scale eddy transport of angular momentum, heat (Molinari and Vollaro 1989, 1990), and potential vorticity (Molinari et al. 1995, 1998) that may vary in connection with the storm PV structure evolution. Its impact on the mean tangential flow acceleration can be assessed with Eliassen-Palm (E-P) fluxes (Hartmann et al. 1984) computed in a stormfollowing cylindrical and isentropic framework for an adiabatic frictionless f plane.' The relative eddy angular momentum flux convergence (REAMFC; Molinari and Vollaro 1989) is a simpler parameter that can be used to quantify the spin-up of a storm's tangential circulation on a given pressure level due to asymmetric eddies (from Rossby wave activity, for example). Azimuthal eddy flux of angular momentum shows import or inward flux of cyclonic momentum in the upper troposphere within rapid intensification cases - the primary features that produce such fluxes are outflow jets and approaching troughs. The REAMFC is usually computed at $200 \mathrm{hPa}$ over a $300-600-\mathrm{km}$ radial range around the TC centre. An interaction is generally said to occur when the REAMFC exceeds $10 \mathrm{~m} \mathrm{~s}^{-1}$ day $^{-1}$ for at least two consecutive 12-h time periods (DeMaria et al. 1993; Hanley et al. 2001). This parameter acts as a measure of the outflow layer spin-up of the TC as a trough comes into the aforementioned annulus.

The geometry of the TC-trough system has been revealed as important in determining how TC intensity will be influenced by a trough (Wei et al. 2016; Leroux et al. 2016; Fischer et al. 2017). Consistent with observational evidence pointing to the importance of upshear convection on TC intensification after genesis (e.g. Galarneau et al. 2013), North Atlantic TCs experiencing rapid intensification just after genesis feature TC-trough configurations that promote stronger quasigeostrophic ascent to the left of, and upshear of, the TC centre and more symmetric convection compared to TC-trough configurations where TCs remain at essentially the same intensity (see Fig. 10; Fischer et al. 2017). Overall, these recent studies suggest that intensification is sensitive to the location of the TC relative to the exact position and shape of a nearby trough. In particular, Komaromi and Doyle (2018) found that TC-trough interactions are most favourable for intensification when the relative distance between the TC and the trough is $0.2-0.3$ times the wavelength of the trough in the zonal direction and $0.8-1.2$ times the amplitude of the trough in the meridional direction.

TCs can interact with their environment, such as upper level systems, in regions where their inertial stability is the lowest due to reduced resistance to radial perturbations. The inertial stability of an axisymmetric vortex in gradient balance is defined by many sources (e.g. Holland 1987):

$$
I^{2}=(f+\zeta)\left(f+2 \frac{v}{r}\right)
$$

where $f$ is the Coriolis parameter, $v$ the azimuthal mean tangential wind, and $r$ the radius or distance to the centre computed in a storm-following cylindrical framework. The maximum inertial stability is located in the lower eyewall where the winds and cyclonic rotation are maximum. It is lowest at upper levels in the 
TC outflow and is also low through mid-levels where outflow is generally weak. $I^{2}$ may evolve in time for TCs impacted by a mid-latitude trough, which will be illustrated for ex-TC Oswald.

Two heavy rain events following the landfalls of TC Fitow (2013) and TC Bilis (2006) on the China coast were examined by Bao et al. (2015) and both Deng et al. (2017) and Gao et al. (2009) respectively. In both cases, the torrential rain occurred at some $400 \mathrm{~km}$ from the storm's centre. Bao et al. (2015) present compelling evidence that the Fitow event was influenced by a rapidly evolving favourable environment. The large-scale flow changes appeared to provide (1) inflow channels into the rain area, which influenced the vertical, kinematic structure over the rain area, and hence the ascent field, and (2) regions for active frontogenesis and its associated secondary circulation, with enhanced ascent over the rain area. Deng et al. (2017) offer a PV perspective of the vortex structure changes of TC Bilis during the heavy rain event. The increased deformation and weakening of vertical vorticity as Bilis approached the monsoon trough contributed to the storm evolving from a closed, tight circulation into a loosely distributed circulation. As a result of the induced pressure and wind anomalies associated with this structure change, an increase in gradient wind imbalance in the mid-levels redistributed high PV air from the inner core to outer radii. This redistribution of $\mathrm{PV}$ explained the rapid decline of the inner core circulation and provided a direct lifting mechanism for convection within the outer rainband over land.

In the following sections, we will enlarge upon these issues for the Oswald case, introduce some additional synoptic- and meso-scale aspects, analyse some backward trajectories from Oswald circulation to evaluate the influence of environmental flow changes and discuss the relevance of these to the production of heavy rain. The interaction will be described in terms of $\mathrm{PV}$ injection from the environment into the storm circulation, and its impact on the storm will be defined using a detailed PV and angular momentum analysis. We will also use the turning wind with height thermal advection diagnostic (Tory 2014; Callaghan and Tory 2014) to explain the location and intensity of rainfall. The major objective is to provide quantitative evidence that the large-scale circulation changes influenced the efficiency of the rain systems by producing a highly favourable thermodynamic and kinematic environment. 'What maintained the circulation for such a long time after it made landfall?' is the critical question to answer here.

The manuscript is organised as follows: Section 2 describes the track of ex-TC Oswald as well as the chronology of the heavy rain event while listing the serious rain and wind impacts. Section 3 presents the data used in the study. Section 4 illustrates the Rossby wave breaking event and the resulting evolving synoptic-scale flow. Section 5 describes the thermodynamic and kinematic structure of the ex-TC Oswald circulation and its close environment. Section 6 examines the interaction within the PV framework. Section 7 shows results from backward trajectory calculations, used to illustrate possible interactions with the storm's environment. Section 8 uses angular momentum and other considerations to provide interpretation of the interactions between the environment and the ex-Oswald circulation, consistent with the backward trajectories; it shows how the environmental interaction became strongly conducive to tornado genesis as ex-TC Oswald moved further down the coast. Section 9 is the summary and conclusion.

\section{Impacts of rain and wind from ex-tropical cyclone Oswald}

The following description is largely based on Australian Bureau of Meteorology (2013b), Special Climate Statement 44 extreme rainfall and flooding in coastal Queensland and New South Wales. The Insurance Council of Australia estimated the cost of the ex-TC Oswald event at \$853 million.

The track and intensity of Oswald are shown in Fig. 1. Locations of place names used in the text are also indicated. At landfall, the central pressure of the system was estimated at $990 \mathrm{hPa}$. The main feature is that the pressure did not rise much over land even over south-east Queensland when the centre was well inland. In the several days following landfall, the storm even slightly intensified over land and maintained a central pressure of $\sim 990 \mathrm{hPa}$ as it travelled slowly southward. Note that Oswald was slowly moving from 2000 UTC 24 January to 1500 UTC 26 January. Most of the eastern coastal and mountain areas of Australia, extending from $\sim 12$ to $30^{\circ} \mathrm{S}$, experienced very heavy rainfall during the period from 22 to 29 January (Fig. 2f). The heavy rain coincided with the passage of the ex-TC Oswald circulation. Note the relatively large regions with accumulated rainfall in excess of $200 \mathrm{~mm}$ day $^{-1}$ that extend southward of exTC Oswald for days 23-27 January (Fig. 2a-e). Fig. $2 c$ and $d$ shows very heavy rain on 25 and 26 January when Oswald was slowly moving. On 25 January, areas around Rockhampton recorded rainfall exceeding $300 \mathrm{~mm}$ for a 24-h period (Fig. 2c). More interestingly, 24-h total rainfall amounts continued to increase as the storm gained speed after 1800 UTC 26 January (Fig. 2e) and further interacted with its environment (Sections 4-8).

Significant rainfall flood totals are indicated in Table 1 and Fig. 3. Rainfall for the areas between Rockhampton and Gympie alone were heavy enough to break the January monthly rainfall records. The most extreme daily rainfall for the week occurred on 27 and 28 January over the Gold Coast Hinterland and New South Wales border catchment and the edge of the Brisbane river catchment where rainfall for a 24 -h period was in excess of $700 \mathrm{~mm}$ (Mt Castle and Springbrook, Table 1). The Queensland State Emergency Service received 1800 calls for help in $24 \mathrm{~h}$ on 28 January, mostly in the south-east areas of the state. Although the Lockyer Creek, Bremer River and the Brisbane River flooded (Table 1), impacts in Brisbane were not as severe as the 2011 floods. Torrential rainfall and flooding also occurred in northern New South Wales particularly near Lismore (Table 1) where evacuations occurred, $\sim 2000$ in total. The New South Wales State Emergency Service attended to over 2900 calls for assistance, mostly in the North of the state. Eight New South Wales river systems had flood warnings in place.

Tragically, seven people were killed due to the extreme weather over the course of the week. Thousands were forced to evacuate and 2000 people were isolated by floodwaters for some days. Key infrastructure was damaged and destroyed, estimated to cost hundreds of millions of dollars. The rail service was closed between Cairns and Townsville, the Weipa port shut 


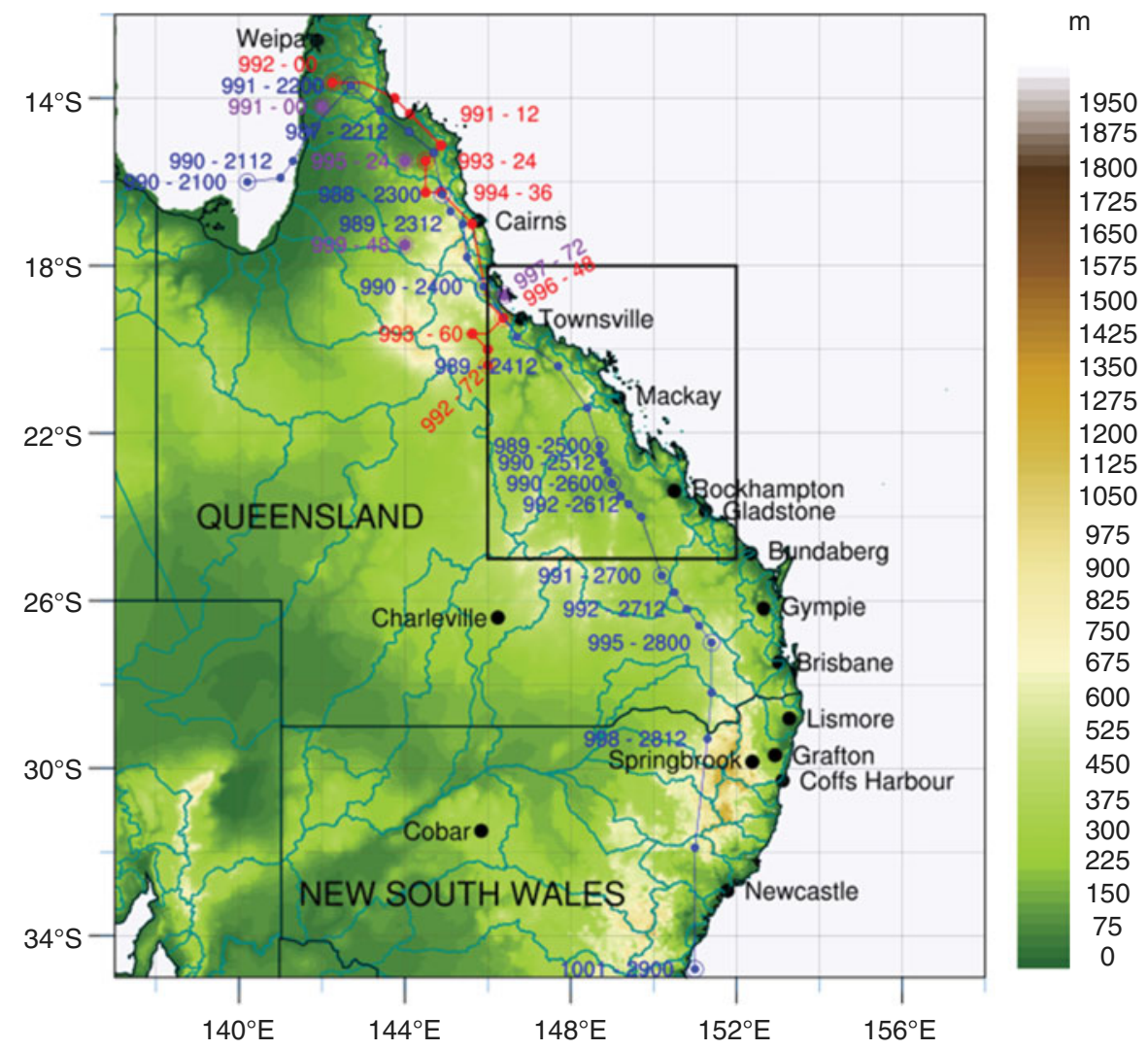

Fig. 1. Best track of Oswald (in blue) showing locations every $6 \mathrm{~h}$ and central pressure every $12 \mathrm{~h}$ with legend ppp-ddhh, where $\mathrm{ppp}=$ central pressure and ddhh = day-time (hour UTC), on top of topography (shaded) and main rivers (in cyan). The 72-h ACCESS-R (IFS) forecast from 0000 UTC 22 January 2013 is shown in red (purple) with locations every $6 \mathrm{~h}(24 \mathrm{~h})$ and central pressure every $12 \mathrm{~h}(24 \mathrm{~h})$ with legend $\mathrm{ppp}-\mathrm{hh}$, where $\mathrm{ppp}=$ central pressure and $\mathrm{hh}=$ forecast-time (hours). A black rectangle shows the area used for averages in Fig. 10. Locations are encircled at 0000 UTC synoptic times. ACCESS-R, Australian Community Climate and Earth System Simulator-Regional; IFS, Integrated Forecast System.

down for several days, airlines cancelled many domestic flights between New South Wales and Queensland, and the worst ever power outages occurred in Queensland affecting 283000 properties. Overall, Bundaberg was the worst affected city with 2000 homes and 200 businesses inundated with floodwater. The Burnett River was running at $\sim 70 \mathrm{~km} \mathrm{~h}^{-1}$ and threatened to sweep houses away. Despite a mandatory evacuation, 18 helicopters were utilised in a rescue effort evacuating more than 1000 people trapped by floodwaters in North Bundaberg and other most-at-risk areas, which was a record evacuation effort in Australia. On 31 January, in North Bundaberg, 7000 residents were forced out of their homes.

At many sites, heavy rainfall was accompanied by coastal storm surges and big waves, several tornadoes (particularly in the Bundaberg area on Saturday 26 January) as well as strong winds with wind gusts in excess of $100 \mathrm{~km} \mathrm{~h}^{-1}$. When overland on the east coast, there was no maximum wind near the centre of the storm; the peak winds and tornadoes were well to the south-east under the rainband and warm air advection (WAA) (see Section 5). On Sunday 27 January, the system impacted Brisbane, the Gold Coast and Sunshine Coast with damaging to destructive winds, ${ }^{1}$ torrential rain, dangerous surf and tidal inundation for a 24-h period. Winds reached $131 \mathrm{~km} \mathrm{~h}^{-1}$ at Cape Byron. The wind impacts can be summarised in Table 2. In summary this was a major, high-impact weather event that needed to be documented and understood.

\section{Data sources}

The Australian Bureau of Meteorology (BOM) operates a suite of numerical weather prediction (NWP) models, named the Australian Community Climate and Earth System Simulator (ACCESS) (Australian Bureau of Meteorology 2012, 2013a, 2013b). Objective analyses used in this study are mostly obtained from ACCESS-G (Australian Community Climate and Earth System Simulator-Global, Australian Bureau of Meteorology 2012; Puri et al. 2013) at $0.5^{\circ}$ resolution. Comparisons

\footnotetext{
${ }^{1}$ In the Australian context, 'damaging winds' are defined as 3-s gusts over open flat land in the range $90-124 \mathrm{~km} \mathrm{~h}^{-1}$. 'Destructive winds' are defined as 3-s gusts over open flat land of $125-164 \mathrm{~km} \mathrm{~h}^{-1}$.
} 


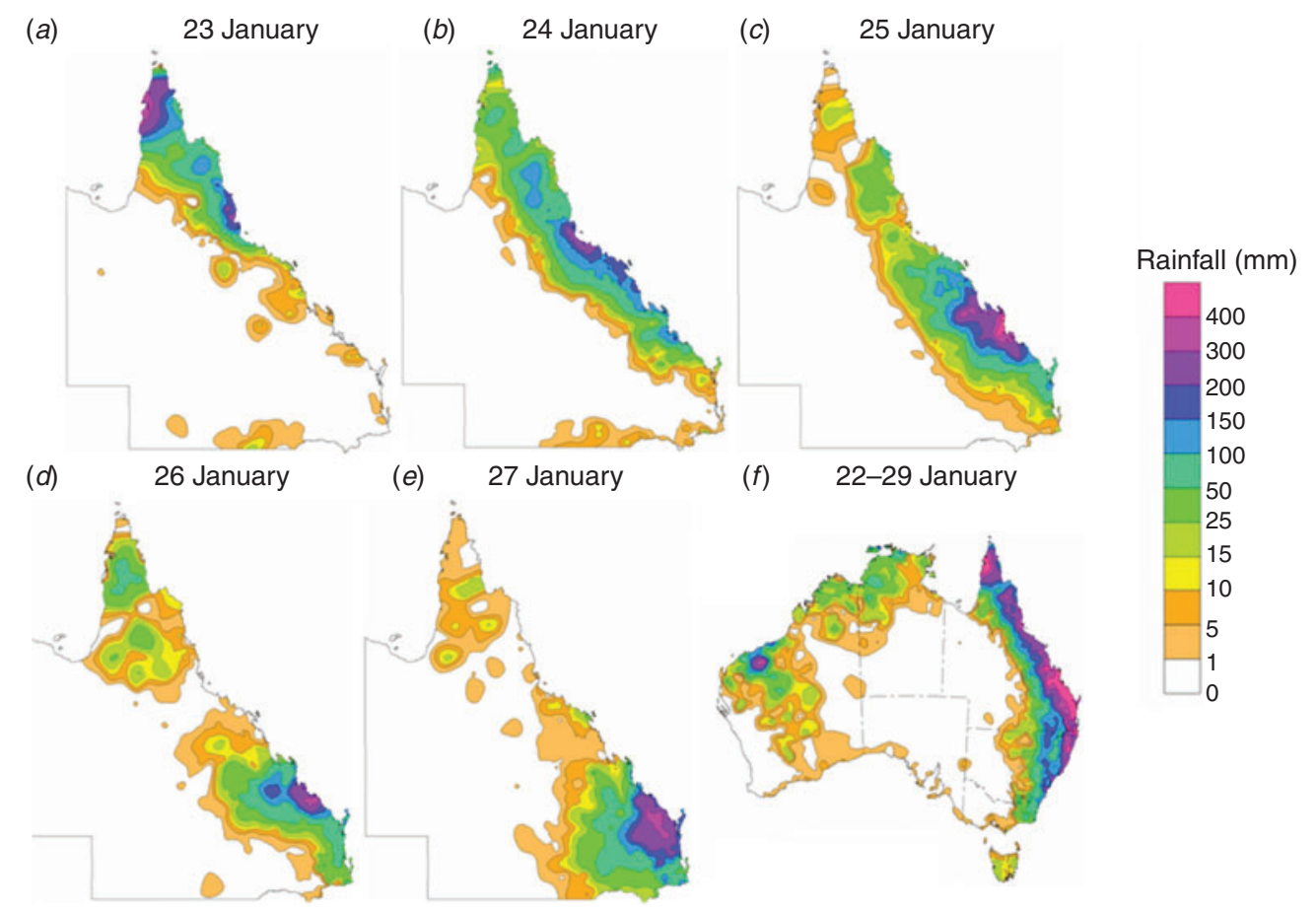

Fig. 2. (a-e) Accumulated daily rainfall totals over Queensland for days 23-27 January and $(f)$ accumulated 7-day rainfall over Australia for the period 22-29 January 2013. These diagrams were obtained from the Bureau of Meteorology site: http://www.bom.gov.au/jsp/awap/rain/index.jsp, accessed 7 May 2020.

Table 1. Summary of significant rainfall flood totals associated with Oswald; records are underlined

\begin{tabular}{|c|c|c|c|}
\hline City & Period & Rainfall amount & Previous record \\
\hline Maryborough & Daily rainfall & $258.8 \mathrm{~mm}$ & $250.7 \mathrm{~mm}(1893)$ \\
\hline Mt Castle & Daily rainfall (2300 UTC 26-27 January) & $709 \mathrm{~mm}$ & \\
\hline Springbrook & Daily rainfall (2300 UTC 26-27 January) & $744 \mathrm{~mm}$ & \\
\hline Ingham and Tully & 3-day total rainfall & $1000 \mathrm{~mm}$ & \\
\hline Burnett river at Bundaberg & $2.6 \mathrm{~m}$ predicted & $9.3 \mathrm{~m}$ & \\
\hline Bremer river & $15 \mathrm{~m}$ predicted & $13.9 \mathrm{~m}$ & \\
\hline Brisbane river & & $2 \mathrm{~m}$ & \\
\hline Clarence River at Grafton & Just below the flood levee wall & $8.09 \mathrm{~m}$ & \\
\hline Laidley creek & & $\frac{9.26 \mathrm{~m}}{\text { January }}$ on 28 & $8.85 \mathrm{~m}$ (January 2011) \\
\hline
\end{tabular}

were also made with operational analyses from the global European Centre for Medium-Range Weather Forecasts (ECMWF) Integrated Forecast System (IFS) at $0.25^{\circ}$ resolution to ensure that the processes discussed here were robust and not the artefact of one model only. Operational regional forecasts are from ACCESS-R (Australian Community Climate and Earth System Simulator-Regional, Puri et al. 2013, Australian Bureau of Meteorology 2013a), the limited-area configuration of ACCESS-G, at $0.375^{\circ}$ resolution. ACCESS-R provided a quite skilful forecast of the system's track and intensity from basetime
0000 UTC 22 January 2013, in particular when compared to that from the operational IFS model over the same period of interest (Fig. 1, purple colour).

In ACCESS-R forecasts, the vortex centre is defined as the local extremum in the relative vorticity field at $850 \mathrm{hPa}$. The use of the mass-weighted average of the vorticity centres at different levels, local minimum in the mass field or local maximum in the wind speed give consistent results. The use of $0.375^{\circ}$-resolution outputs prevents any mislocation of the TC centre owing to (1) possible mesovortices with relatively high vorticity in the 

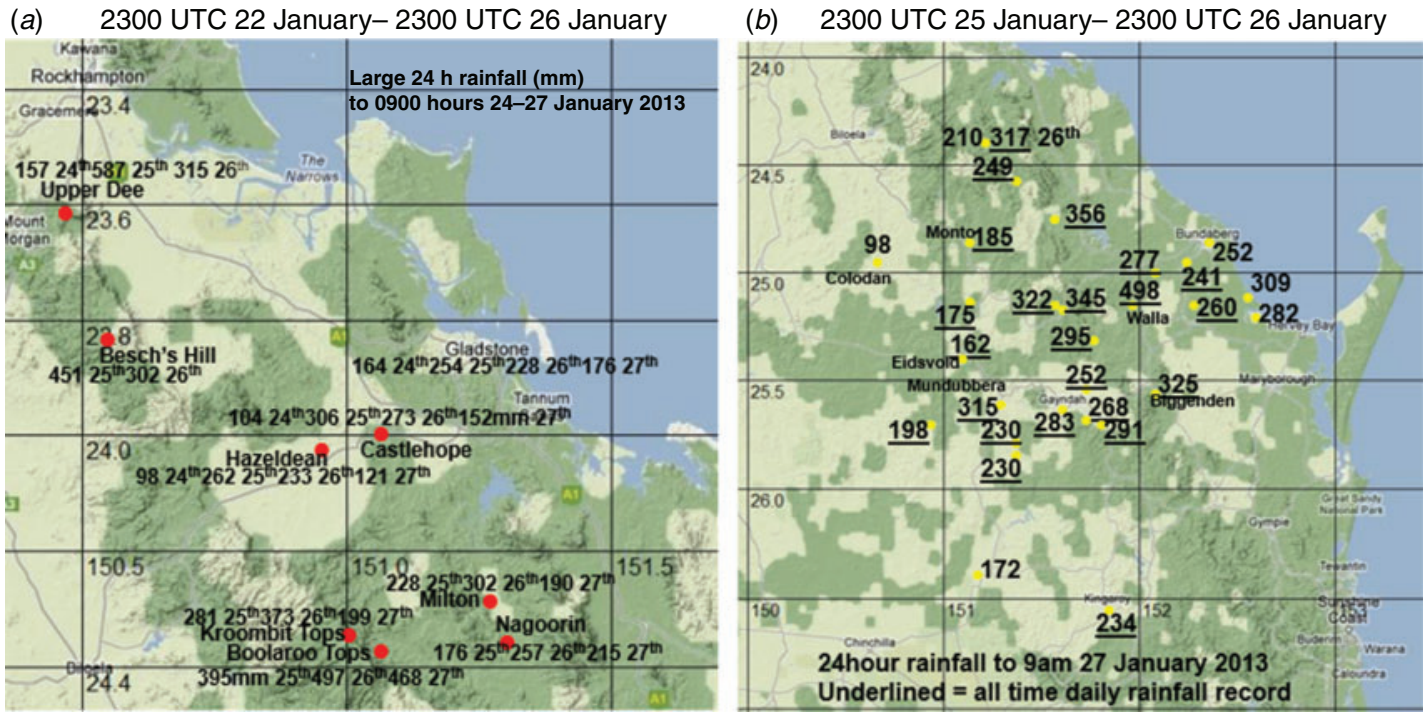

Fig. 3. (a) Heaviest $24-\mathrm{h}$ rainfall $(\mathrm{mm})$ to 0900 hours $24-27$ January 2013 AEST (i.e. UTC $+10 \mathrm{~h}$ ), that is during the period 2300 UTC 22-26 January, in the region near Gladstone. (b) Heavy 24-h rainfall to 0900 hours AEST 27 January (2300 UTC 25-26 January) in and near the Burnett River catchment with all-time record daily rainfall underlined. AEST, Australian Eastern Standard Time.

Table 2. Timeline of significant wind impacts with reports of tornadoes (confirmed) from severe thunderstorms associated with Oswald AEST, Australian Eastern Standard Time; LT, local time (AEST, i.e. UTC+10 h); ENE, east-northeast; NE, northeast; SE, southeast; SSW, south-southwest

\begin{tabular}{|c|c|c|c|}
\hline $\begin{array}{l}\text { Time } \\
\text { (local) }\end{array}$ & Town & Reports & Damage and recorded winds \\
\hline \multicolumn{4}{|c|}{ Saturday 26 January } \\
\hline $1300 \mathrm{LT}$ & Bagara (10-km ENE of Bundaberg) & $\begin{array}{l}\text { Tornado or waterspout } \\
\text { coming ashore from } \\
\text { over water }\end{array}$ & $\begin{array}{l}\text { Two people were critically injured after being trapped in } \\
\text { a car by a fallen tree. Major damage included unroofing } \\
\text { of buildings in town, downed power lines, and a car and } \\
\text { tree which became airborne and dropped into a yard. } \\
\text { A disaster was declared }\end{array}$ \\
\hline $1500 \mathrm{LT}$ & Burnett Heads (10-km NE of Bundaberg) & Tornado & 150 homes reported damage \\
\hline $1500 \mathrm{LT}$ & Coonarr (15-km SE of Bundaberg) & Tornado & Large trees uprooted and strong winds \\
\hline $1608 \mathrm{LT}$ & $\begin{array}{l}\text { ( 40-km SSW of Bundaberg just east of the Bruce } \\
\text { Highway) }\end{array}$ & Tornado & \\
\hline $1820 \mathrm{LT}$ & Burnett Heads (10-km NE of Bundaberg) & Tornado & \\
\hline
\end{tabular}
Sunday 27 January

Bundaberg, Roma, Peel Island

Toowoomba

Redcliffe

Heron Island

Double Island Point

Monday 28 January

Archerfield, Brisbane Airport

Gold Coast Seaway

Spitfire Channel

$90 \mathrm{~km} \mathrm{~h}^{-1} 3$-s gust

$92 \mathrm{~km} \mathrm{~h}^{-1} 3$-s gust

$94 \mathrm{~km} \mathrm{~h}^{-1} 3$-s gust

$100 \mathrm{~km} \mathrm{~h}^{-1} 3$-s gust

$122 \mathrm{~km} \mathrm{~h}^{-1} 3$-s gust

Cape Moreton

$92 \mathrm{~km} \mathrm{~h}^{-1} 3$-s gust
$94 \mathrm{~km} \mathrm{~h}^{-1} 3$-s gust
$96 \mathrm{~km} \mathrm{~h}^{-1} 3$-s gust
$127 \mathrm{~km} \mathrm{~h}^{-1} 3$-s gust

eyewall region or (2) high vorticity associated with cyclonic shear away from the storm centre. A cylindrical framework centred on the TC is chosen to highlight the asymmetric effects of the trough on the TC symmetric circulation; azimuthal means and deviations from those means are computed. Horizontal bilinear interpolation from a uniform (latitude and longitude) grid to cylindrical coordinates (radius $r$ and azimuth $\lambda$ ) is performed with radial resolution of $40 \mathrm{~km}$ and azimuthal 
resolution of $1^{\circ}$. Azimuth $0^{\circ}$ is east, $90^{\circ}$ is north, $180^{\circ}$ is west and $270^{\circ}$ is south. For diagnostics computed in a storm-relative flow, the vortex motion is subtracted from the absolute wind at all grid points prior to cylindrical conversion. The wind shear is averaged over the 200-800-km annulus range to virtually extract the storm vortex (Kaplan and DeMaria 2003).

Real-time rainfall analyses of accumulated precipitation are obtained from the Bureau of Meteorology at http://www.bom. gov.au/jsp/awap/rain/index.jsp, accessed 7 May 2020. The analysis system is described in Jones et al. (2009). The Bureau of Meteorology archived radar images are from http://www. theweatherchaser.com/radar-loop/, accessed 7 May 2020.

The backward trajectories shown here are calculated using the HYSPLIT Lagrangian trajectory system developed at NOAA (Draxler and Hess 1998) and implemented at the Australian Bureau of Meteorology (http://www.wmo.int/ pages/prog/www/DPS/WMOTDNO778/rsmc-melbourne-a. htm, accessed 7 May 2020). The trajectories are based upon 6-hourly data from the ECMWF ERA-Interim reanalysis (Dee et al. 2011) at T255 L60 $\left(0.75^{\circ}\right.$ latitude-longitude resolution with 60 vertical levels).

\section{Track and synoptic-scale flow changes - wave activity}

Apart from its longevity, a peculiarity of the Oswald event is that the cyclone moved parallel to the coastline. The dynamical reasons for this peculiarity are illustrated with a sequence of Global Forecast System (GFS) charts at 850 and $500 \mathrm{hPa}$ from 22 to 25 January with actual wind observations for veracity (Fig. 4). It clearly shows a north-westward steering flow that dominated the circulation which extended up to $500 \mathrm{hPa}$ from 22 to 27 January (26 and 27 January not shown), resulting in a track parallel to the coast. The strong anticyclone over the Tasman Sea (Fig. $5 a, b$ ) may have contributed to this north-westward steering flow and to providing a supply of low-level moisture to the developing system.

Synoptic-scale flow changes are illustrated in Fig. 5 with analyses of mean sea-level pressure and 500- and 200-hPa wind prior to and during the event. Apart from the intensification of the ex-TC Oswald circulation (near $19^{\circ} \mathrm{S}$ and $148^{\circ} \mathrm{E}$ ), the dramatic changes in the large-scale circulation are indicated by (1) the strengthening in major anticyclones over the Indian Ocean and south Pacific Ocean or Tasman Sea (Fig. 5a, b) and (2) the marked amplification of a planetary Rossby wave over higher latitudes. There is evidence of downstream amplification, indicated by the succession of developing troughs (Ts) and ridges (Rs) which propagate towards the north-east (Fig. 5d). There is also evidence of an 'interaction', merger or axisymmetrisation between the propagating wave and ex-Oswald mid-level circulation. Evidence of this is the large increase in the size of the exOswald mid-level circulation (Fig. $5 c, d$ ). This was reflected to some extent in the size of the low-level TC circulation (Fig. 5a,b). Note that the physical explanation for the downstream amplification from mid-latitudes towards the tropics is Rossby wave breaking that leads to the observed structure in the mid- to upper level wind field. The Rossby wave breaking event is clearly shown on isentropic maps of upper tropospheric PV from IFS operational analyses at $25-\mathrm{km}$ resolution (Fig. 6). The strongest $\mathrm{PV}$ values associated with the trough progress towards the tropics from 23 to 24 January. At 0000 UTC 24 January, the trough is located $\sim 1200-\mathrm{km}$ south-southeast of the TC centre (Fig. $6 b, d$ ). Examination of the PV coherent structure associated with the trough at both upper $(350 \mathrm{~K})$ and mid $(330 \mathrm{~K})$ levels suggests that it is highly tilted towards the equator. At $330 \mathrm{~K}$, a PV anomaly of smaller size and amplitude (possibly a cut-off) is advected towards the storm (Fig. 6b), potentially feeding its core with cyclonic PV from 0000 UTC 24 January. A detailed analysis of the PV interaction will be given in Sections 6 and 7.

As part of the amplification, an extended, over-the-sea, easterly trade flow was established to the east of the rain event (Fig. 5b). This occurred in association with the strengthening in the anticyclone over the south Pacific. We propose that this also likely provided a continuous supply of moisture for the persistent heavy rain ahead of the southward moving cyclonic circulation. Rainfall was almost certainly modulated by local topography as moist boundary layer air in the extended easterly flow, associated with the evolving large-scale environment, was lifted to release conditional instability.

\section{Thermodynamic and kinematic structures of ex-tropical cyclone Oswald}

The local kinematic and thermodynamic structure of ex-TC Oswald is illustrated in Figs 7 and 8. Figure $7 a$ shows radarbased rainfall rates from a composite of Townsville-Gladstone radar reflectivities superimposed on the mean sea-level pressure analysis at 2300 UTC 23 January 2013. The centre of ex-TC Oswald was located just to the north-west of Townsville with radar indicating moderate patchy rain along the coast to the south, where the $700-\mathrm{hPa}$ flow was directed from the warm side of the $850-500-\mathrm{hPa}$ vertical wind shear to the cold side of it (Fig. 7b), implying WAA or moist isentropic ascent and heavy rainfall (Callaghan 2017a, 2017b; Callaghan and Power 2016; Callaghan and Tory 2014; Tory 2014). A nice illustration is to look at Brisbane airport at 2300 UTC 26 January when storm force winds are turning anticyclonically with height from 850 to $500 \mathrm{hPa}$ (Fig. $8 e$, see the vertical wind shear in red): $55^{\circ} / 55 \mathrm{kts}$ at $850 \mathrm{hPa}, 45^{\circ} / 54 \mathrm{kts}$ at $700 \mathrm{hPa}$ and $5 \% 56 \mathrm{kts}$ at $500 \mathrm{hPa}$. The associated rainfall in the following $24 \mathrm{~h}$ was $709 \mathrm{~mm}$ at Mt Castle (247 mm fell in the $9 \mathrm{~h}$ following 2300 UTC 26 January) and $744 \mathrm{~mm}$ at Springbrook, which are huge totals for the subtropics.

The WAA pattern, indicated by the red streamlines, is associated with the general system-scale cyclonic circulation in an environment with nontrivial temperature gradients in the low-to mid-troposphere (e.g. Figs. $7 b, e$ and $8 b, e$ ). This gradient appears to be the combination of a general meridional temperature gradient, with a cold-dome super-imposed in the southern edge of the storm (creating a distinct cold-ridge, Fig. 7b,e) associated with the passage of a tropopause undulation above (Fig. 7c, f). The upper level cyclonic PV anomaly casts a shadow all the way to the surface, inducing adiabatic ascent for mass continuity, which lifts the isentropes and provides localised cooling (Hoskins et al. 1985), that is, the 700-hPa cold air centre evident on Fig. 7b, e. The WAA is a direct result of that cold air centre. A southward tilt of the storm (Fig. 7e, $f$ ) is also consistent with this temperature structure. The heavy rainfall (Figs 7a, $d$ and $8 a, d$ ) is consistent with the diagnosed WAA pattern and occurs to the south of the storm centre. This region also 
(a)

$850 \mathrm{hPa}-0000$ UTC 22 January 2013

(b) $\quad 500 \mathrm{hPa}-0000$ UTC 22 January 2013
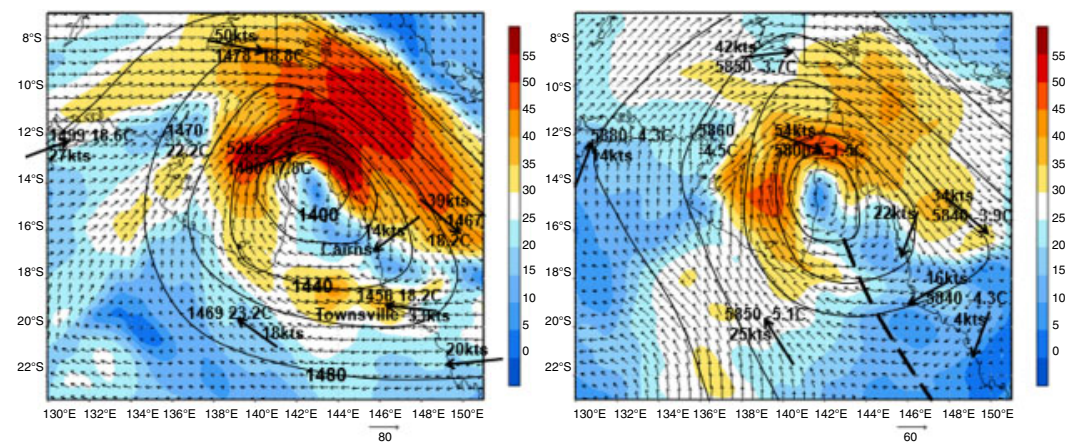

(c)

$850 \mathrm{hPa}-0000$ UTC 23 January 2013

(d) $500 \mathrm{hPa}-0000$ UTC 23 January 2013
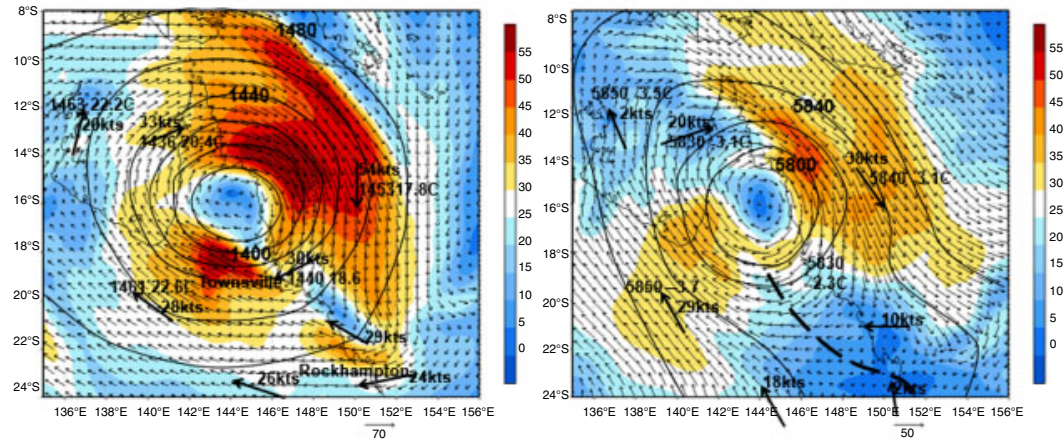

(e)

$850 \mathrm{hPa}-0000$ UTC 24 January 2013
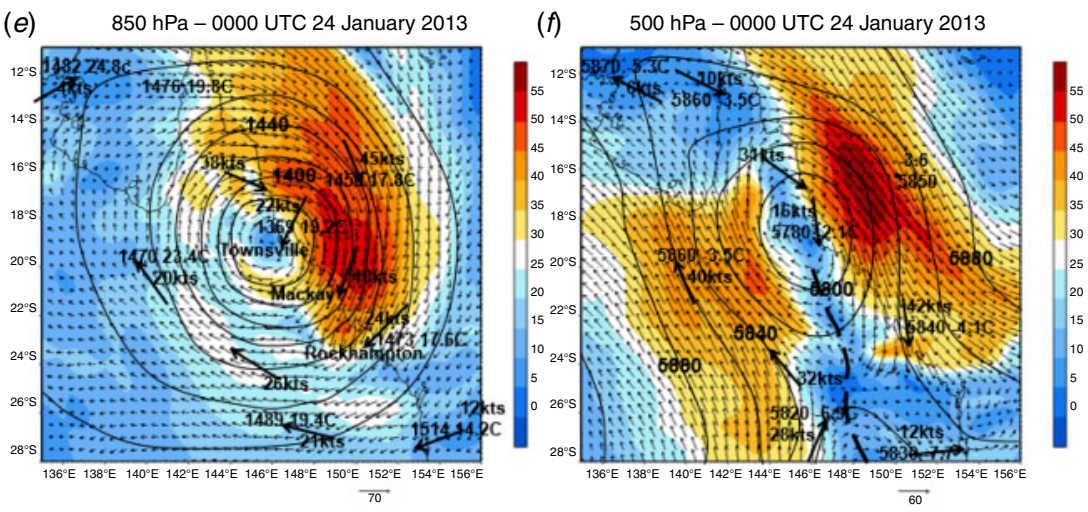

(g) $850 \mathrm{hPa}-0000$ UTC 25 January 2013
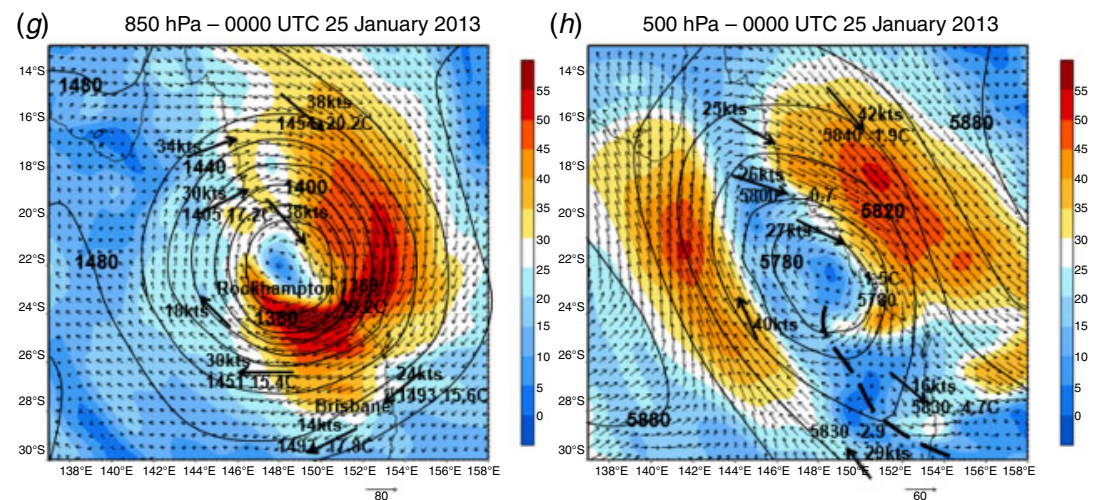

Fig. 4. Global Forecast System wind analyses (knots) at (left frames) $850 \mathrm{hPa}$ and (right frames) $500 \mathrm{hPa}$ for $(a, b) 0000$ UTC 22 January, $(c, d) 0000$ UTC 23 January, $(e, f) 0000$ UTC 24 January and $(g, h) 0000$ UTC 25 January 2013. Actual observations of wind, temperature and geopotential height $(\mathrm{m})$ are plotted where available. 
(a) MSLP - 0000 UTC 20 January 2013

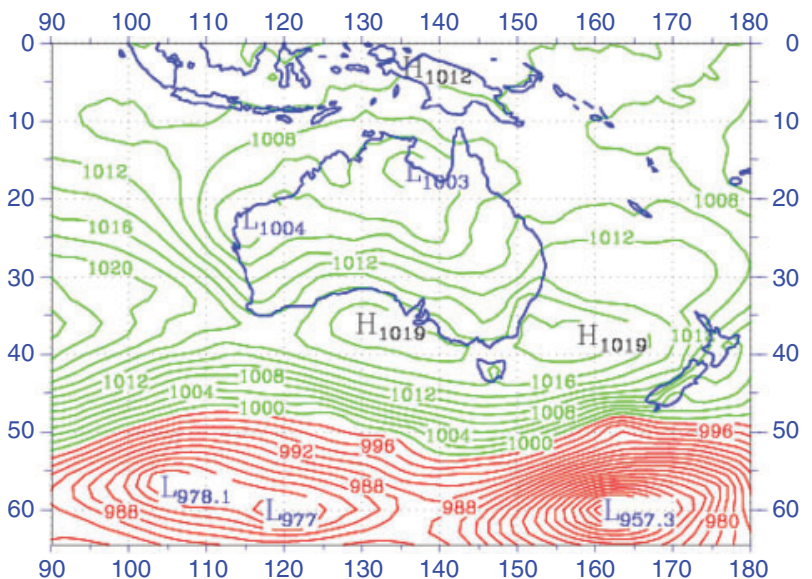

(c) WIND $500 \mathrm{hPa}-0000$ UTC 20 January 2013

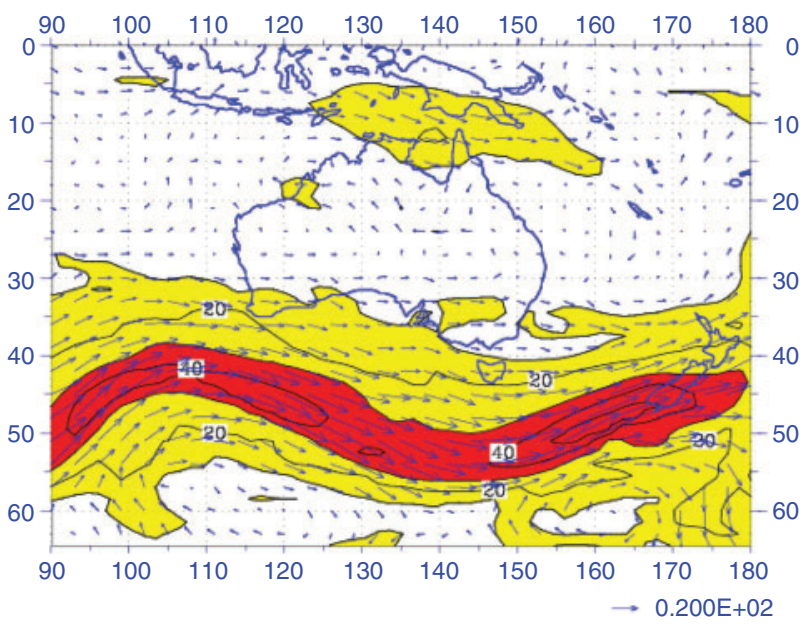

(e) WIND $200 \mathrm{hPa}-0000$ UTC 20 January 2013

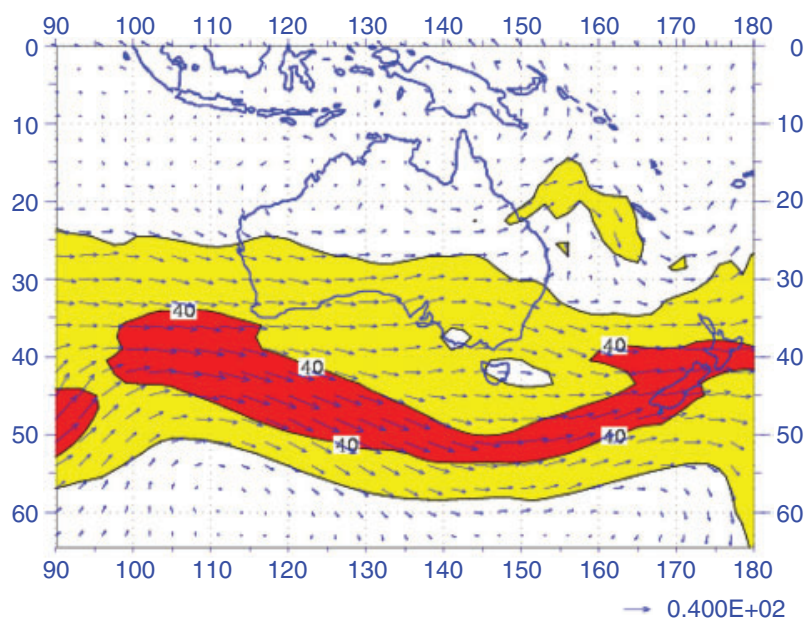

(b) $\quad$ MSLP - 0000 UTC 24 January 2013

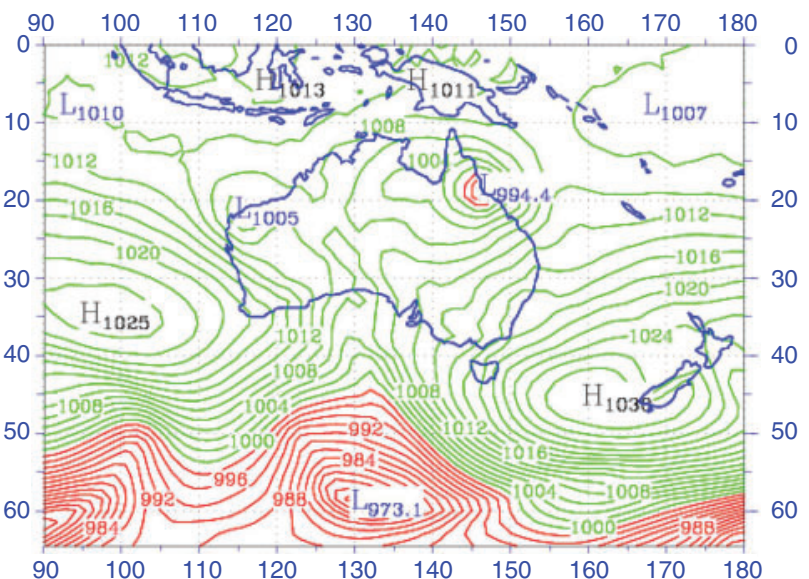

(d) WIND $500 \mathrm{hPa}-0000$ UTC 24 January 2013

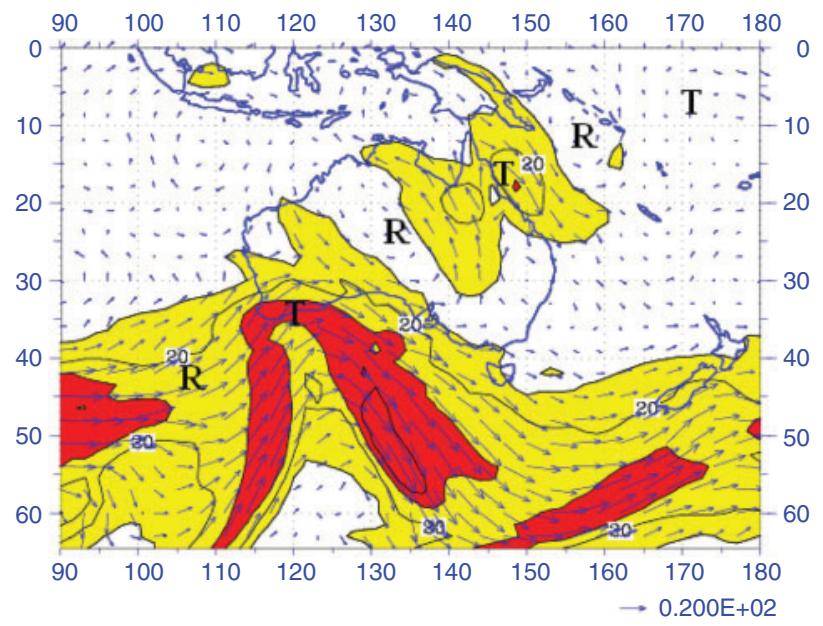

(f) WIND $200 \mathrm{hPa}-0000$ UTC 24 January 2013

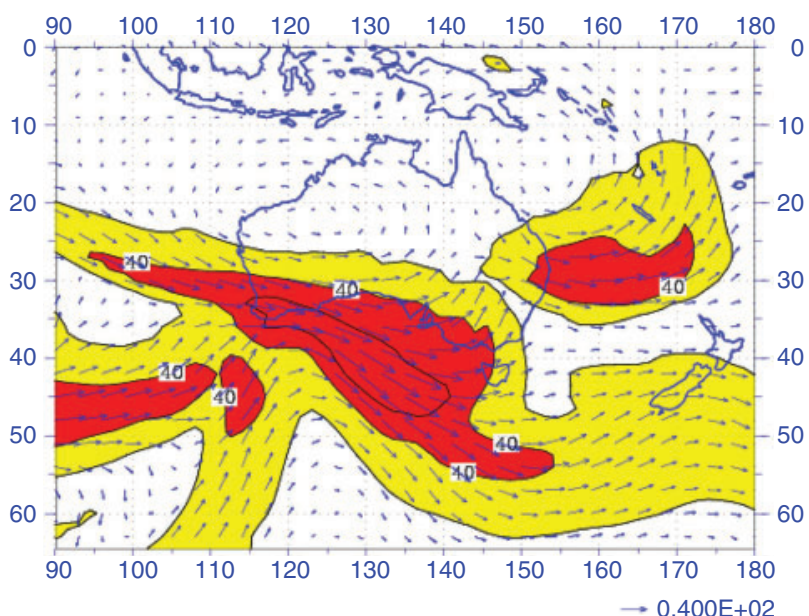

Fig. 5. Australian Community Climate and Earth System Simulator-Global analyses of $(a, b)$ mean sea-level pressure (MSLP), $(c, d) 500-\mathrm{hPa}$ winds and $(e, f) 200-\mathrm{hPa}$ winds, valid at $0000 \mathrm{UTC} 20$ January (left panels) and 24 January (right panels) 2013. Contour interval for MSLP is $2 \mathrm{hPa}$. At $500 \mathrm{hPa}$, contour interval is $10 \mathrm{~m} \mathrm{~s}^{-1}$, with winds greater than $10 \mathrm{~m} \mathrm{~s}^{-1}$ and less than $30 \mathrm{~m} \mathrm{~s}^{-1}$ shaded yellow, and winds greater than $30 \mathrm{~m} \mathrm{~s}^{-1}$ shaded red. At $200 \mathrm{hPa}$, contour interval is $20 \mathrm{~m} \mathrm{~s}^{-1}$, with winds greater than $20 \mathrm{~m} \mathrm{~s}^{-1}$ and less than $40 \mathrm{~m} \mathrm{~s}^{-1}$ shaded yellow, and winds greater than $40 \mathrm{~m} \mathrm{~s}^{-1}$ shaded red. (d) Troughs and ridges are indicated by $\mathrm{T}$ and $\mathrm{R}$ symbols respectively. 
(a)

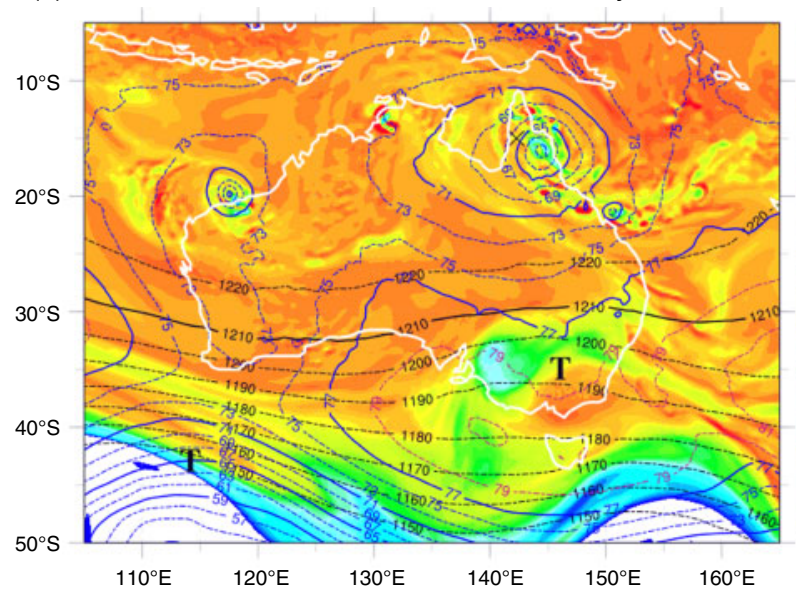

(c)

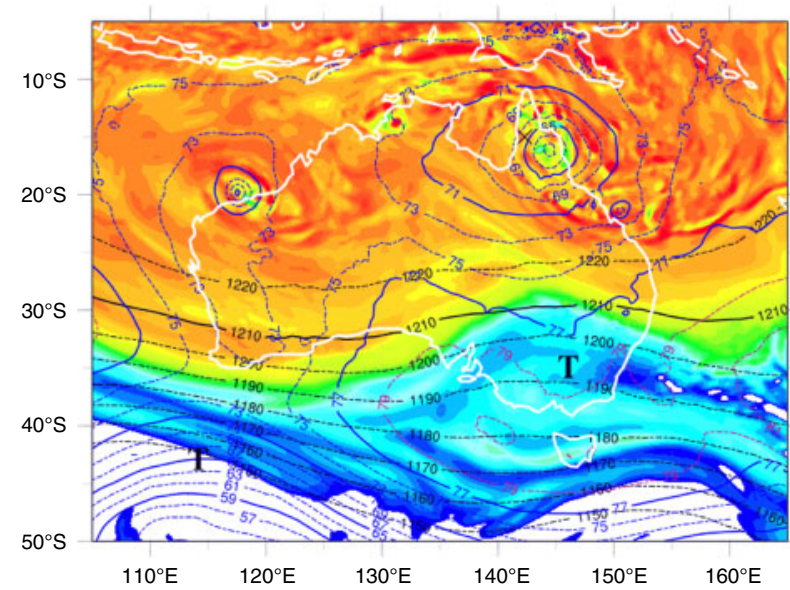

(b)

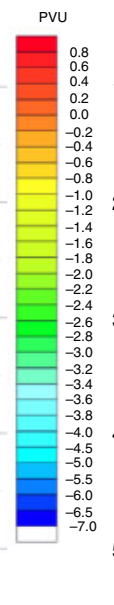

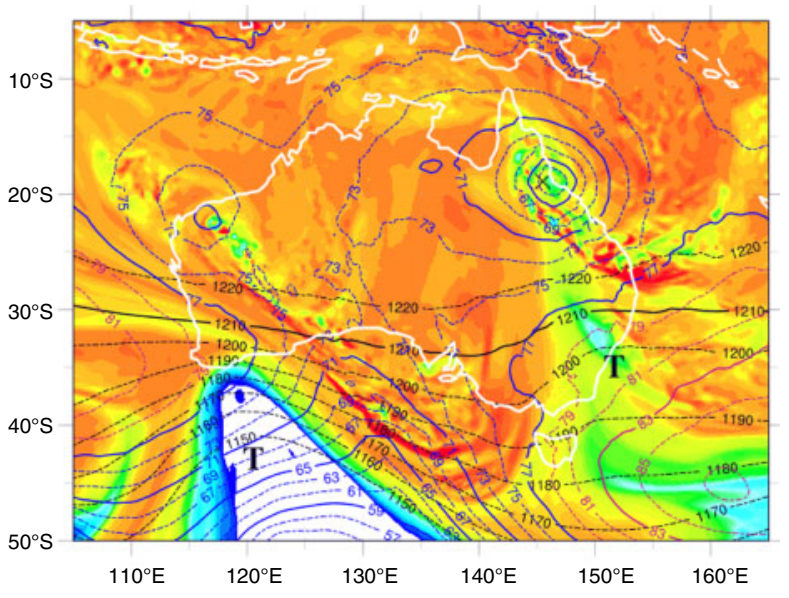

(d)

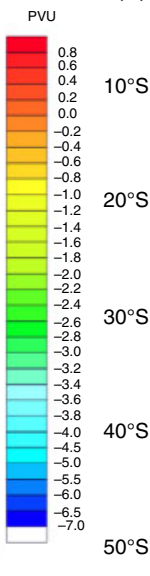

350 K - 0000 UTC 24 January 2013

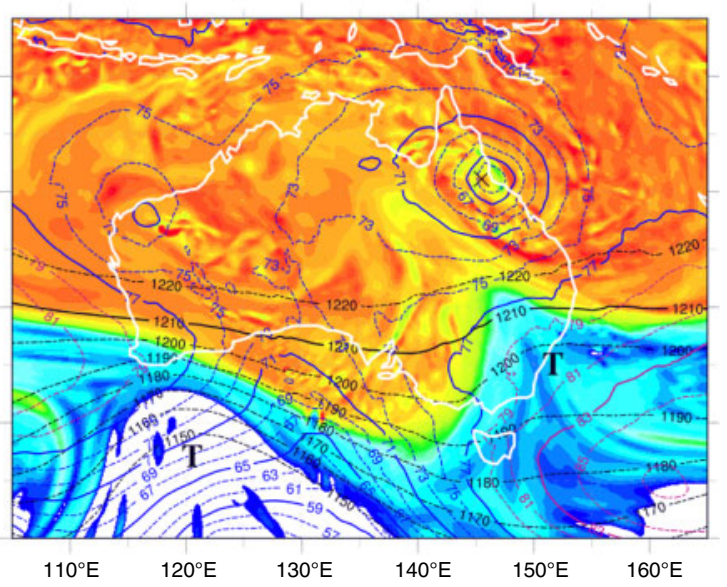

Fig. 6. Integrated Forecast System operational analyses valid at 0000 UTC 22 January (left panels) and 24 January (right panels) 2013. Plotted are the Ertel potential vorticity (PV) field on the $(a, b) 330-\mathrm{K}$ or $(c, d) 350-\mathrm{K}$ isentropic surfaces (shaded; $1 \mathrm{PVU} \equiv 10^{-6} \mathrm{~m}^{2} \mathrm{~K} \mathrm{~s}^{-1} \mathrm{~kg}^{-1}$ ), the geopotential height Z (mgp) at $200 \mathrm{hPa}$ (black contours), and the geopotential height $\mathrm{Z}$ (mgp) at $925 \mathrm{hPa}$ (blue contours for lows and red contours for highs). Oswald's best track centre is indicated by a cross. Troughs are indicated by a $T$ symbol.

experiences topographic lifting of the moist boundary layer easterlies (Section 4), which would have also favoured rainfall. Note that the strengthening of the WAA pattern (Fig. 8b, e) from 26 January coincides with the heaviest rain (Section 2, Figs. 2 and 3). In the case of ex-TC Oswald, the strength of the WAA along with the high dew points highlighted in Figs $8 a, d$ and 9 can, therefore, explain the extreme rainfall from 24 to 27 January (Section 2) that occurred as the storm was interacting with its environment.

Another indication of the WAA set-up is the cold air advection (CAA) counterpart downstream. A broad band of descent flows northward towards the vicinity of the excyclone circulation. This analysis suggests a link with a deep descending current from the tropopause undulation up to the circulation of the cyclone as the undulation passed south of the cyclone, which will be further discussed in the PV analysis (Section 6). Note that the deep descending current from the tropopause is also a typical indicator for TCs undergoing ET (e.g. observational analysis by Quinting et al. 2014 and modelling study by Euler et al. 2019). Note that the classical ET structure with a trough to the west was not evident for Oswald. Instead there was a merger, as PV from the trough was axisymmetrised to become part of the TC circulation through mid-levels. It would be interesting to investigate in more depth what differentiated the Oswald interaction from ET.

To illustrate the vertical structure of the storm, Fig. 10 shows forecast time-height sections from the operational regional forecast model ACCESS-R. Sections are computed over a rectangular latitude-longitude box $\left(18-25^{\circ} \mathrm{S}\right.$ and $\left.146-152^{\circ} \mathrm{E}\right)$ that represents the environment preceding the passage of the storm through the box (Fig. 1). Note that at the initial time of the forecast the storm was located near $14^{\circ} \mathrm{S}, 142^{\circ} \mathrm{E}$, well to the north-west of the box (Fig. 1). The zonal wind section (Fig. 10a) shows the strengthening in the low-level easterlies and upper level westerlies as the storm approaches and begins to feel the effects of the low-level easterlies and upper level westerlies associated with the evolving environment. Relative humidity 
(a)

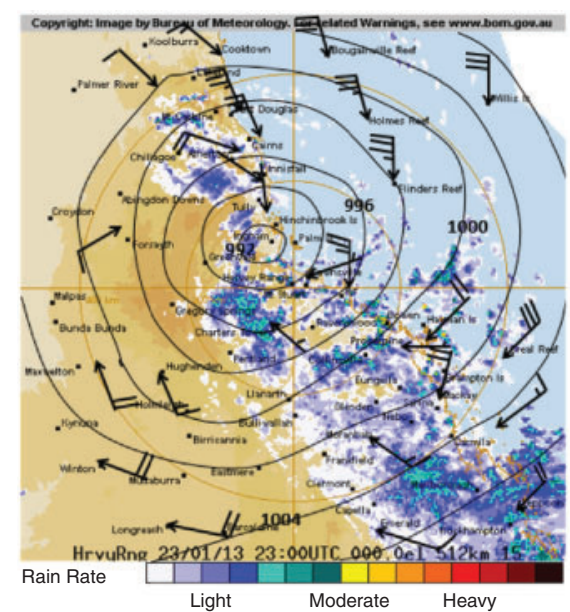

(b)
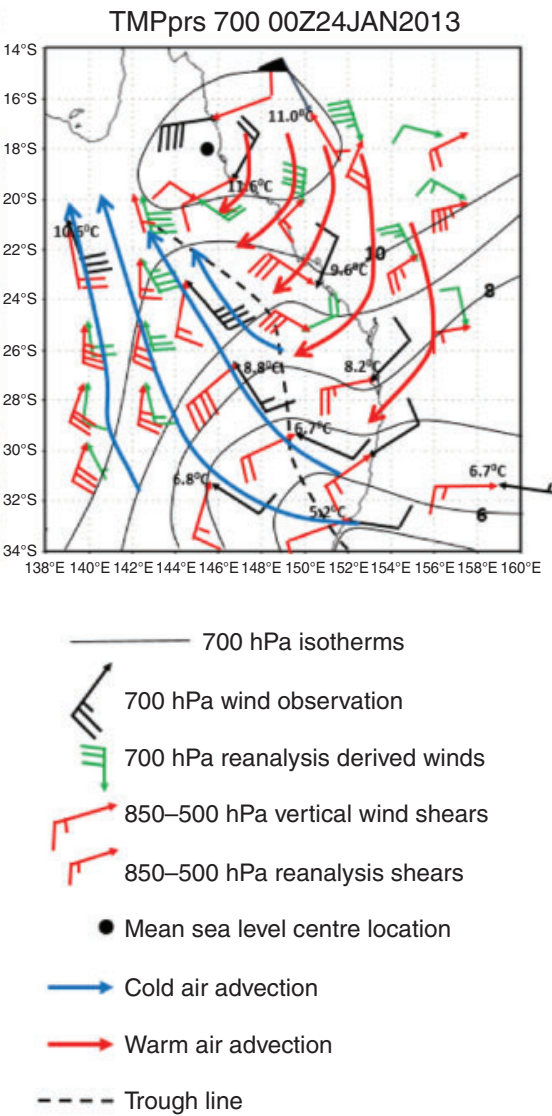

$(e)$
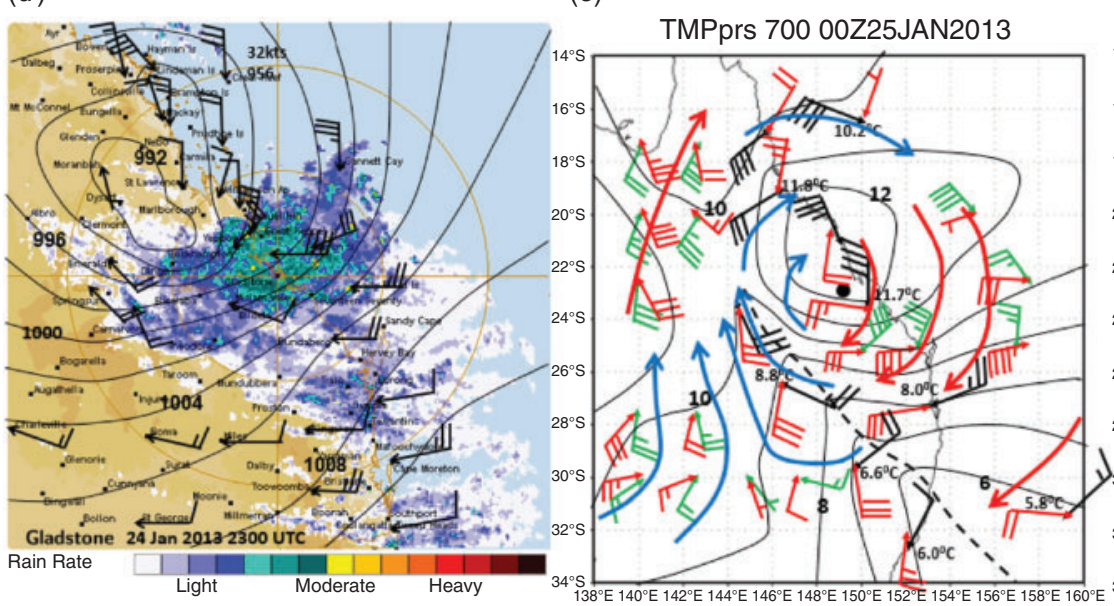

(c)

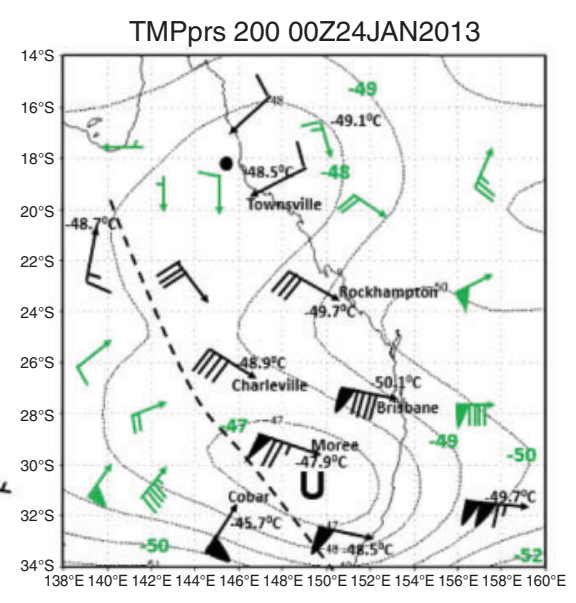

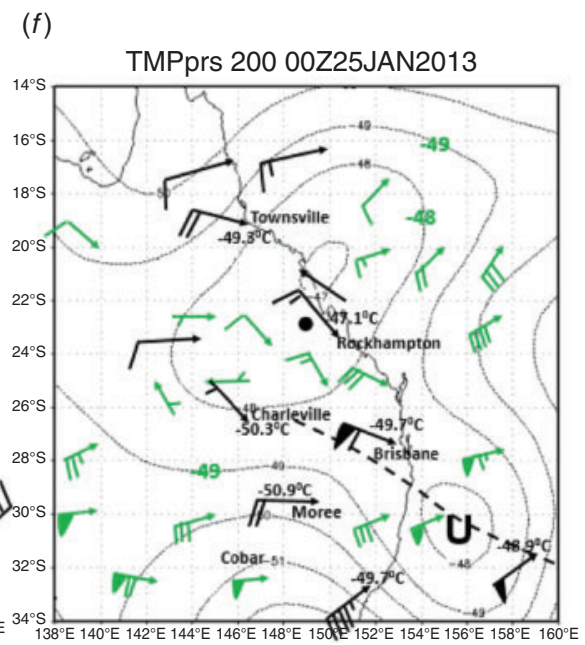

Fig. 7. (a, $d)$ Sea-level isobars and averaged winds overlaid on radar imagery for $(a)$ Townsville at 2300 UTC 23 January and $(d)$ Gladstone at 2300 UTC 24 January. ( $b, e$ ) At 0000 UTC from 24 to 25 January: 700-hPa winds overlaid on isotherms (solid black contours plotted at $1^{\circ} \mathrm{C}$-interval) with $850-500$-hPa vertical wind shear in red (smaller barbs representing wind shear computed from reanalysis winds). Green wind barbs are 700-hPa reanalysis winds, whereas larger black barbs are actual $700-\mathrm{hPa}$ wind observations. Actual temperatures are plotted in black $\left({ }^{\circ} \mathrm{C}\right)$, solid black circle denotes cyclone position, large blue streamlines denote cold air advection (implying descent) and red streamlines denote warm air advection (implying ascent). (c, $f$ ) At $0000 \mathrm{UTC}$ from 24 to 25 January: 200-hPa winds overlaid on 200-hPa reanalysis isotherms with actual 200-hPa temperatures plotted in black; green wind barbs are 200-hPa reanalysis winds; ' $\mathrm{U}$ ' denotes position of tropopause undulation; the dashed line is a trough line. The reanalysis data are from the US site https:// www.esrl.noaa.gov/psd/data/gridded/data.ncep.reanalysis.html, accessed 7 May 2020. 
(a)

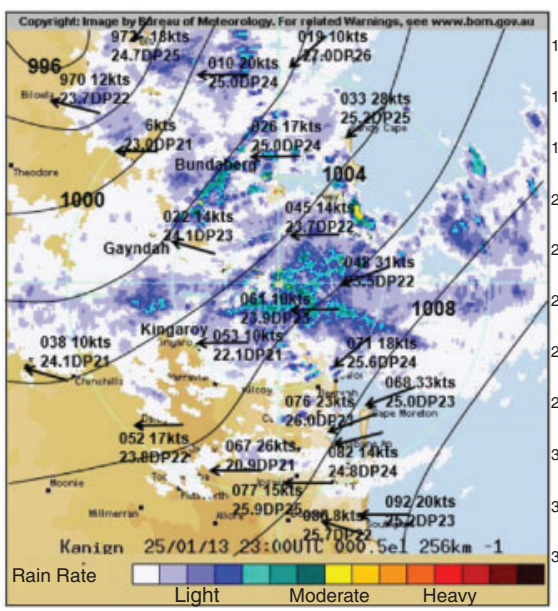

(b)

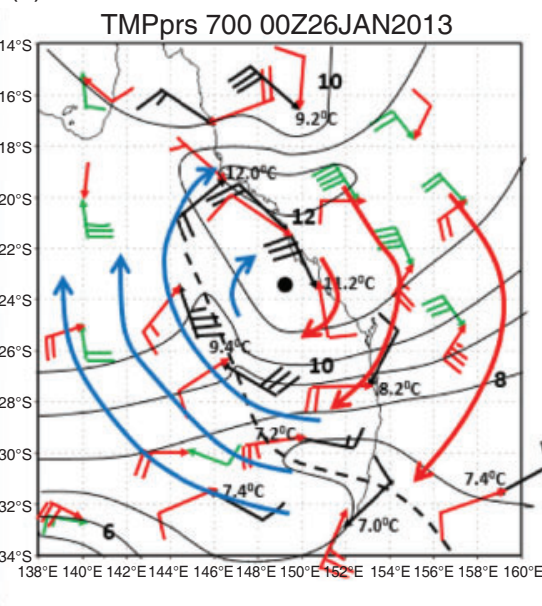

(c)

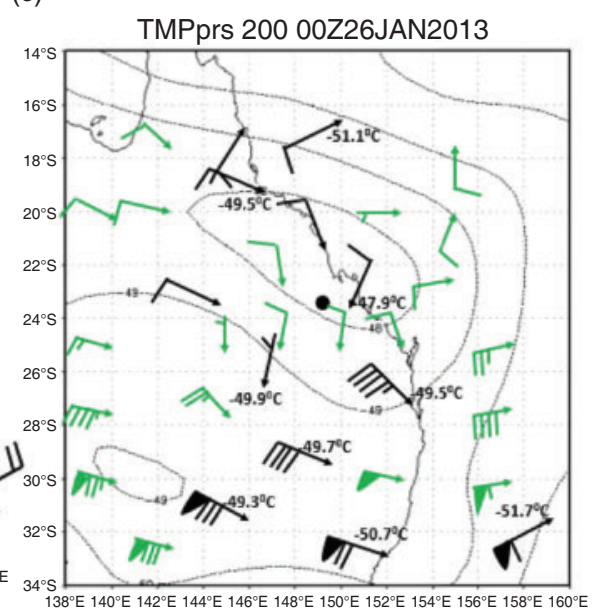

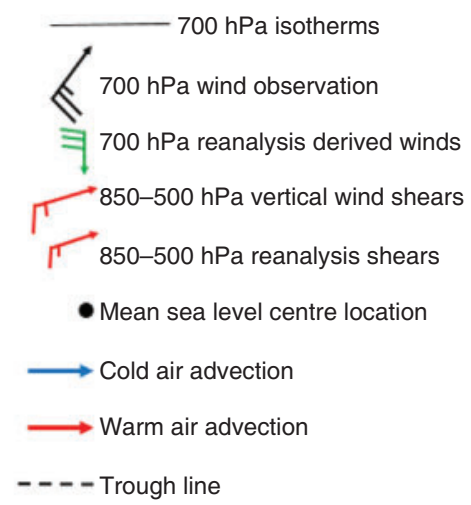

(e)

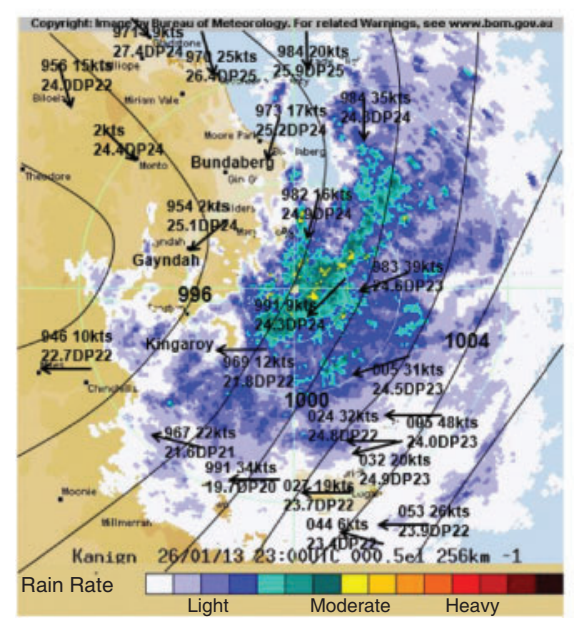

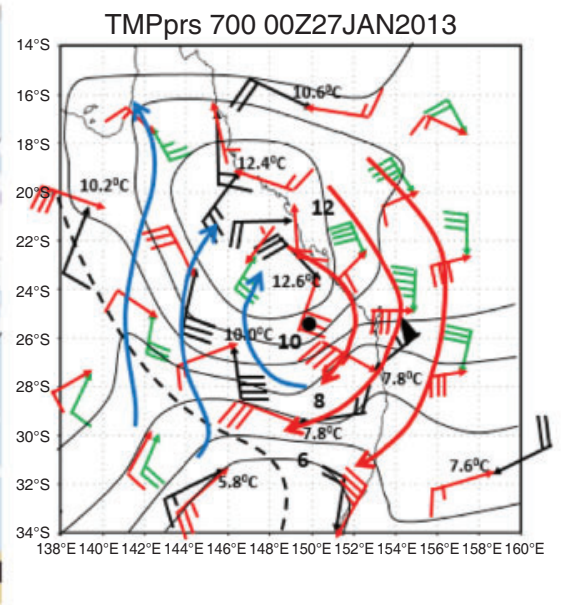

(f)

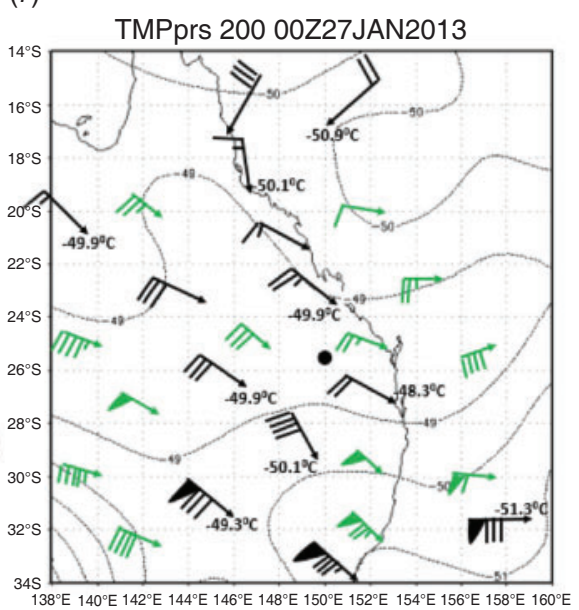

Fig. 8. As in Fig. 7 but for ( $a$ ) Gympie at 2300 UTC 25 January and ( $d$ ) Gympie at 2300 UTC 26 January. Panels $(a, d)$ also show observed MSLP (three digits after the decimal point), wind in knots, temperature and dew point DP. Panels ( $b, c, e$ and $f$ ) as in Fig. 7 but at 0000 UTC from 26 to 27 January. DP, dew point.

(Fig. 10b) shows moistening through a deep layer to values in excess of $80 \%$ through mid-levels and greater than $90 \%$ at low levels. In accordance, theta-e increases in vertical gradient prior to the arrival of the storm (Fig. 10c). There was, thus, increasingly large conditional and convective instability present in the lead up to and during the heavy rain. Time sections of horizontal divergence and ascent are shown in Fig. 10d, e. Deep convergence with a maximum in the boundary layer and troposphericdeep ascent was increasing as the storm approached. Figure $10 f$ shows the time section of PV. Increases in low level and 
(a)

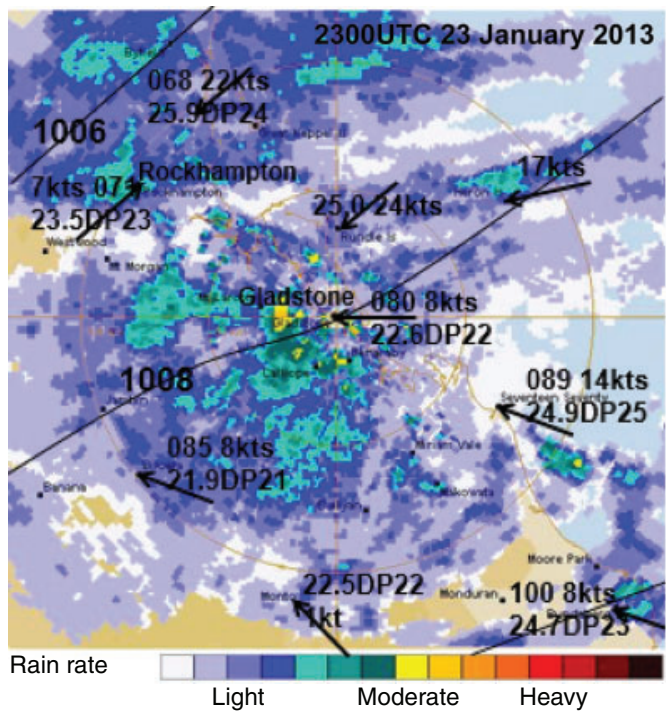

(b)

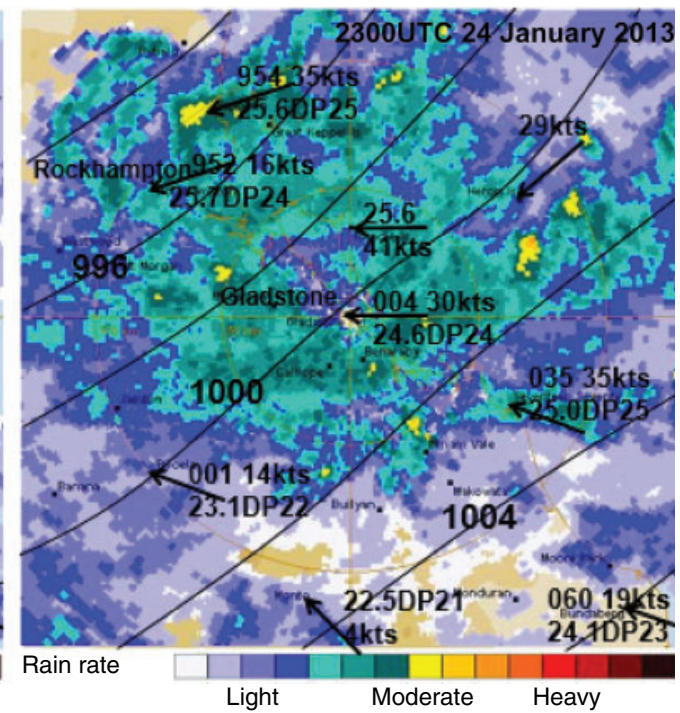

Fig. 9. Gladstone radar imagery with isobars and observations (mean sea-level pressure - 3 digits after the decimal point, wind in knots, temperature and dew point, DP) overlayed for (a) 2300 UTC 23 January 2013 and (b) 2300 UTC 24 January 2013.

(a)

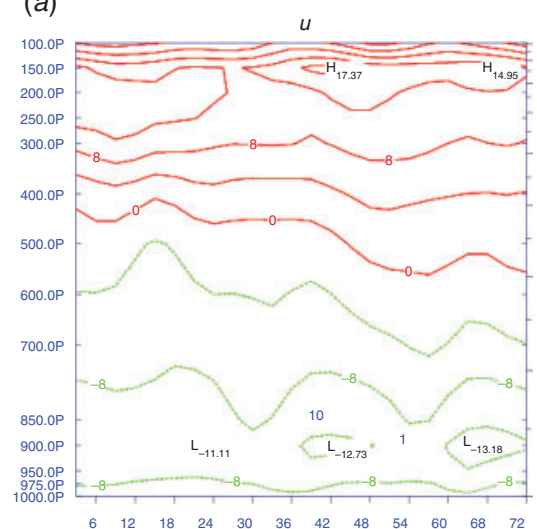

(d)

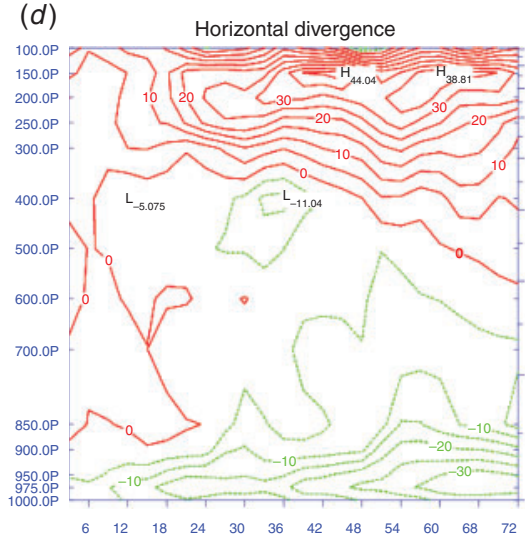

(b)

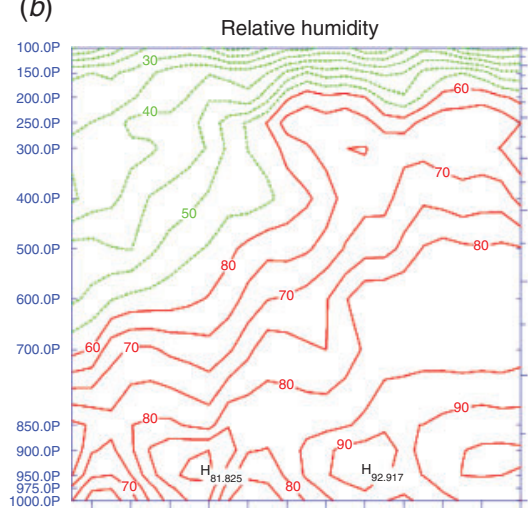

(e)

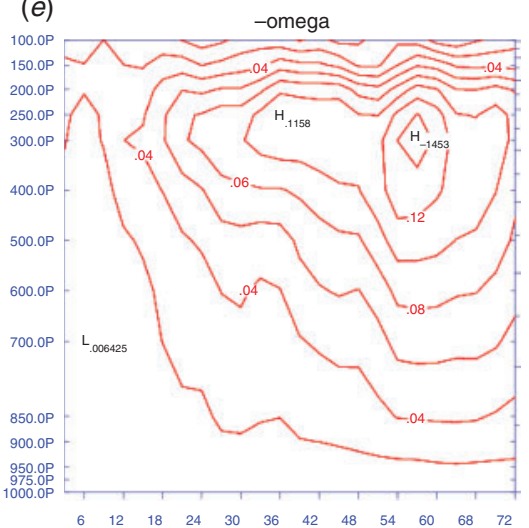

(c)

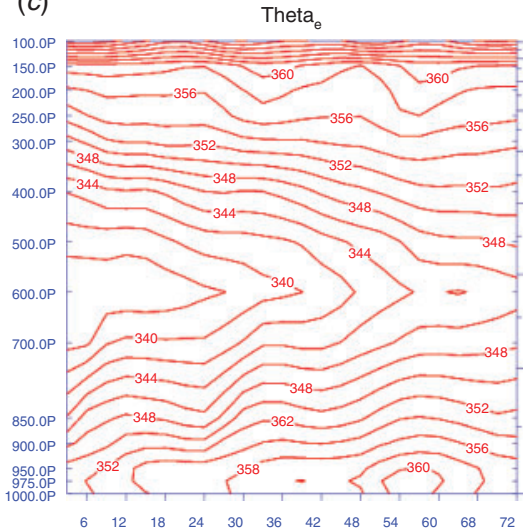

$(f)$

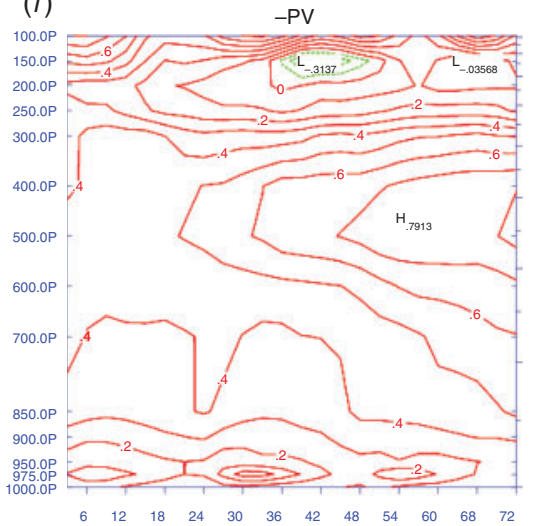

Fig. 10. Time-height series of zonal wind ( $\mathrm{m} \mathrm{s}^{-1}$, contours from -12 to 16 by 4 ), relative humidity ( $\%$, contours from 10 to 95 by 5 ), equivalent potential temperature $\left(\theta_{e}, \mathrm{~K}\right.$, contours from 338 to 372 by 2$)$, horizontal divergence $\left(10^{-6} \mathrm{~s}^{-1}\right.$, contours from -30 to 40 by 5$)$, - omega $\left(\mathrm{hPa}\right.$ day $^{-1}$, contours from 0 to 0.14 by 0.02 ) and - potential vorticity (PV) units (contours from -0.3 to 0.8 by 0.1 ) over the latitude-longitude box $\left(18-25^{\circ} \mathrm{S}, 146-152^{\circ} \mathrm{E}\right)$ drawn in Fig. 1. Input data is at 3-hourly intervals out to $72 \mathrm{~h}$ from Australian Community Climate and Earth System Simulator-Regional forecast from base time 0000 UTC 22 January. 
(a)

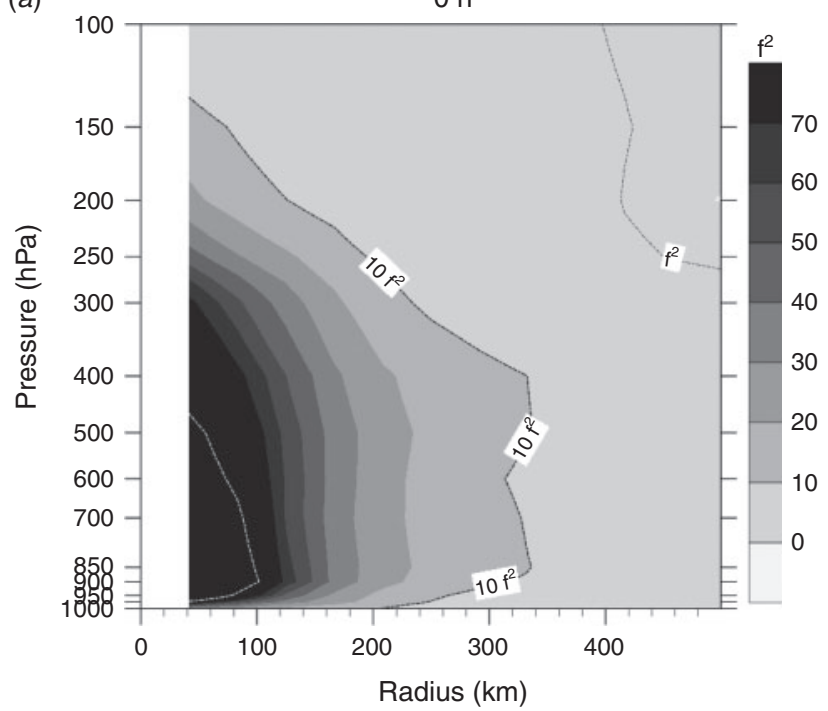

(b)

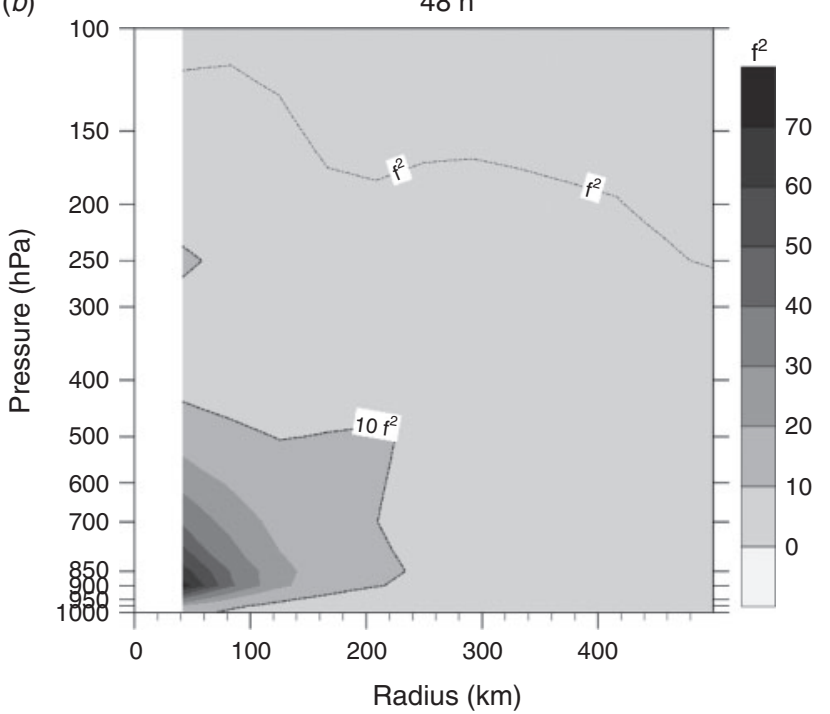

Fig. 11. Vertical distribution of the azimuthal-mean inertial stability $I^{2}$ expressed as multiples of the Coriolis parameter $f^{2}\left(\mathrm{~s}^{-2}, \operatorname{shaded}\right)$ at $(a) 0$ and (b) $48 \mathrm{~h}$ in Australian Community Climate and Earth System Simulator-Regional forecast from base time 0000 UTC 22 January. Oswald's centre is located at the left. Dashed black contours represent $I^{2}$ values of either $f^{2}$ or $10 f^{2}$, whereas dashed white contours are for $I^{2}$ values of $100 f^{2}$.

decreases in upper level PV are evident. An interesting aspect is the inertially unstable flow at upper levels that develops during the rainfall. We speculate that an inertially weak environment was established by the large-scale flow changes (see Fig. $5 f$ and the anticyclonically curved outflow channel), which became unstable as outflow and divergence from the rain system increased. This environment of low inertial stability (Fig. 11) would provide favourable conditions for mass to exit the rain area. We note that the critical ingredients for heavy rain, namely moisture, instability and ascent (Doswell et al. 1996) were present. But we ask the question: What factors were influencing the development of these favourable conditions?

\section{Potential vorticity analysis of the synoptic interaction}

The extratropical-tropical 'interaction' is illustrated in Fig. 12, which shows, from the operational regional forecast model ACCESS-R, the north-south cross sections of PV and vertical motion (omega) through the centre of the ex-Oswald circulation at key times of the interaction. The Oswald circulation can be seen as the PV tower moving from $\sim 14$ to $19^{\circ} \mathrm{S}$. The development of the environmental PV anomaly can first be seen over high latitudes at upper levels (Fig. 12a). The PV anomaly then extends to mid-levels and moves equatorward, as part of the downstream development (Davidson et al. 2008) shown in Fig. 5 (Fig. 12b-d). The PV structure associated with the Rossby wave is highly tilted towards the equator, that is, towards the storm. This tilt favours the merging of the PV anomaly and the exOswald circulation through mid-levels (Fig. 12d,e). The storm also becomes tilted (towards the trough) after $54 \mathrm{~h}$, favouring the merging process and the maintenance of an upper level inflow layer $(\sim 500-300 \mathrm{hPa})$ located below the storm's outflow layer (Fig. 12e). Figure $12 b-d$ indicate that the PV anomaly is likely and understandably influencing the ascent within the Oswald circulation as it approaches the ex-TC. During the merging time, forecast ascent within the circulation continues to increase.

Between 24 and $60 \mathrm{~h}$, the trough-induced inflow is located in the south-southwestern quadrant of the storm (from 210 to $280^{\circ}$, not shown); it affects a deep 600-150-hPa layer and penetrates into the $1200-\mathrm{km}$ radius volume to eventually reach the TC core at mid-levels. In contrast, outflow is observed over the whole 0 $1200-\mathrm{km}$ radius range and above $600 \mathrm{hPa}$ in the eastsoutheastern quadrant (from 300 to $360^{\circ}$ ), leading to a strong outward advection of storm vorticity in the south-eastern quadrant (not shown). Such PV regions may have been associated with heavy rainfall. Note that ex-TC Oswald is constrained by a moderate to strong environmental wind shear that peaks at 8 to $9 \mathrm{~m} \mathrm{~s}^{-1}$ in the ACCESS-R forecast during the 72-h period.

IFS operational analyses at $25-\mathrm{km}$ resolution were also plotted on isentropic coordinates, which is the best way to look at PV advection and Rossby wave activity for pseudoconservative processes (Fig. 6). Time evolution of PV over a deep 330-350-K layer confirms the existence of a PV-coherent structure associated with a Rossby wave breaking event (Fig. 6). At $330 \mathrm{~K}$, a filament of PV with a northwest-south-east orientation is advected towards and feeds the storm from the south from 0000 UTC 24 January (Fig. 6b). The merging process is followed by an axisymmetrisation giving a larger PV core at $400 \mathrm{hPa}$ that continues to be stretched between two adjacent ridges with the trough extending in the northwest-southeast direction (not shown). At higher altitude, such as at $350 \mathrm{~K}$, the strongest cyclonic PV values associated with the 200-hPa trough located south of Oswald do not penetrate beyond $25^{\circ} \mathrm{S}$ latitude (Fig. 6c, d), probably due to the storm's outflow, which prevents the most destructive part of the shear from affecting the storm.

Owing to the deformation and tilting of the trough towards the equator at mid-levels, the trough-induced flow and 
(a)

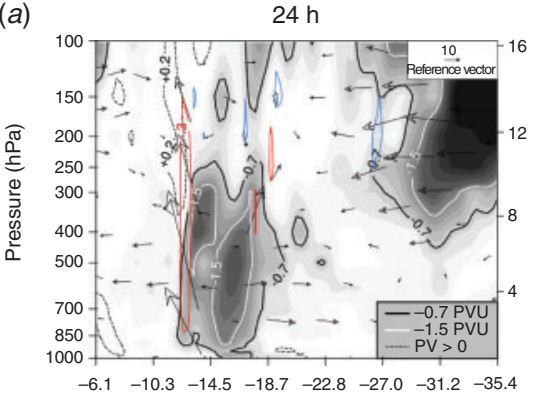

(d)

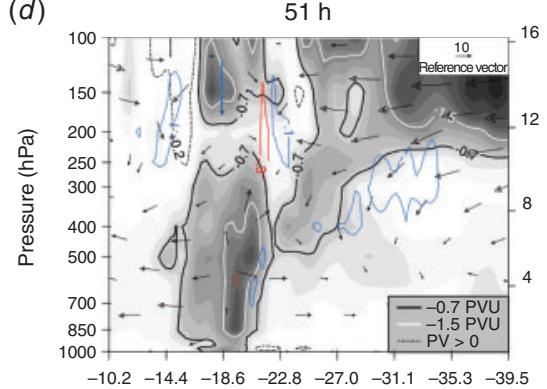

(b)

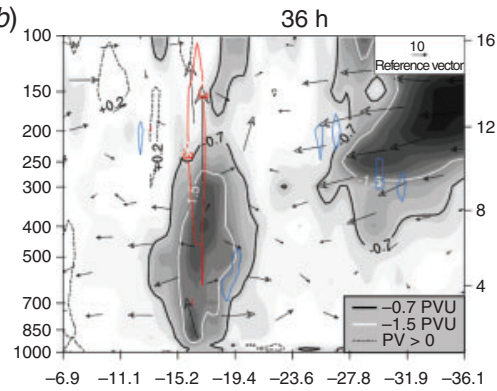

(e)

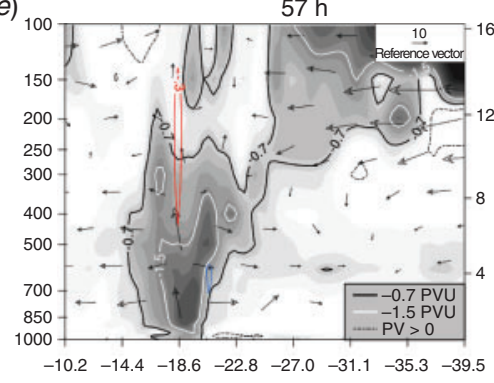

(c)
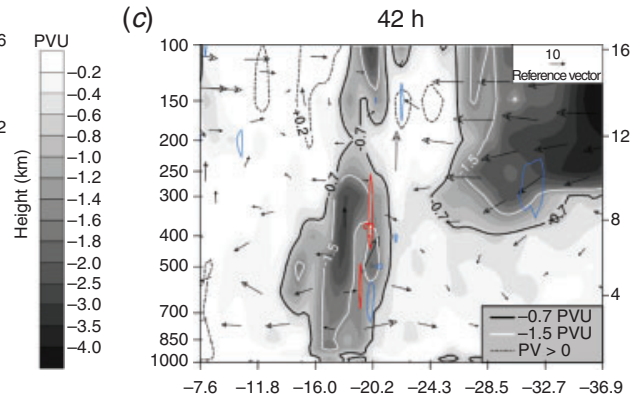

(f)

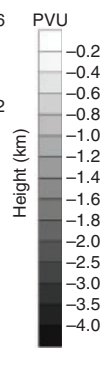

$66 \mathrm{~h}$

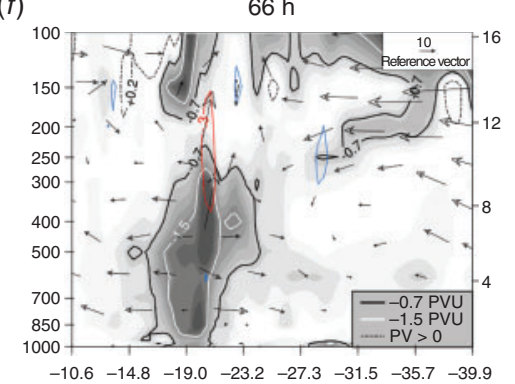

Fig. 12. North-south cross sections of potential vorticity (PVU, shaded) at (a) 24, (b) 36, (c) 42, (d) $51,(e) 57$ and (f) $66 \mathrm{~h}$ in Australian Community Climate and Earth System Simulator-Regional forecast from base time 0000 UTC 22 January. Bottom axis shows the latitudes. Superimposed are PV contours of $-0.7,-1.5$ and 0.2 PVU. The TC centre is located at the left. Arrows represent the radial and vertical $(-100 \times$ omega $)$ wind vectors. Red contours indicate regions of ascent with vertical motion (omega) lower than $-0.3 \mathrm{~Pa} \mathrm{~s}^{-1}$; blue contours indicate regions of descent with vertical motion greater than $0.1 \mathrm{~Pa} \mathrm{~s}{ }^{-1}$.

associated eddy $\mathrm{PV}$ fluxes enable radial advection of cyclonic $\mathrm{PV}$ values $(-u \times \mathrm{PV}<0)$ from the trough into the TC core after $51 \mathrm{~h}$ within a deep tropospheric layer below $400 \mathrm{hPa}$ as indicated by vertical cross sections plotted in the southern sector of the storm (Fig. 13). The advection occurs mostly within the $(600$ 300)-hPa layer and at outer radii, although between 54 and $60 \mathrm{~h}$ the signal connects with the surface layer where radial inflow is also observed at low radii. To our knowledge, this feature has not been observed in previous TC-interaction cases described in the literature.

In conclusion, the storm-trough interaction induces a highly asymmetric process of PV injection (as for TC Dora, Leroux et al. 2013) with much of the action happening at mid-levels. Also, very interestingly here, cyclonic radial PV advection in the southern sector of the storm $\left(240-290^{\circ}\right)$ goes down to the surface and into the ex-TC core between 54 and $60 \mathrm{~h}$. We will demonstrate in Section 8 that this feature is linked to the storm spinning up its low-level circulation in response to enhanced ascent associated with the mid-level PV injection.

\section{Backward trajectories from Oswald circulation}

Changes in the vertical structure of a weather system can influence the vertical motion field associated with the circulation. Omega equations separate adiabatic ascent into two forcing mechanisms (Holton 1979; Hoskins et al. 1985): differential vorticity advection (DVA), and WAA or CAA (WAA or moist isentropic ascent). The DVA concept describes adiabatic vertical motion associated with the evolving atmospheric state. The development of a local cold anomaly is achieved by ascent, which also increases the relative humidity and can trigger convection (hence a developing cold anomaly can be associated with convection and rain). Figures 7 and 8 clearly show WAA, whereas qualitative assessment of the flow fields illustrated in these figures suggests the presence of DVA, which can be associated with adiabatic ascent and associated rainfall from the axisymmetrisation of the PV anomaly. Ascent can also be viewed as the weather system's attempt to rebalance its 3dimensional circulation after the balance is disrupted by changes in its vertical structure. For this event there appeared to be interactions with the environment that influenced the evolution of the rain-producing weather system. In order to quantify these interactions, Lagrangian backward trajectories from Oswald circulation were calculated using the HYSPLIT system documented in Section 3.

A set of grid points (192 at each level, $0.5^{\circ}$ apart), over an area enclosed by a radius of $4^{\circ}$ (Fig. 14), located within a 3dimensional volume centred on the rain system (storm centre) are specified from which backward trajectories are calculated. These points are thus scattered regularly and not biased towards particular regions. We have chosen levels at 1,3 and $7 \mathrm{~km}$ to make the backward trajectories. These were selected based on the examination of the wind analyses at various levels (Fig. 5). The 3-day backward trajectories have been calculated at 6hourly intervals prior to and during the heavy rain: 22-27 January 2013. In addition, at each level we keep track of the area influenced by air coming from the environment (beyond $600 \mathrm{~km}$ from the centre of the rain area) as well as the percentage of PV that comes from the environment. We illustrate the method schematically in Fig. 14. The method allows us to make times series of parameters that define and quantify the 

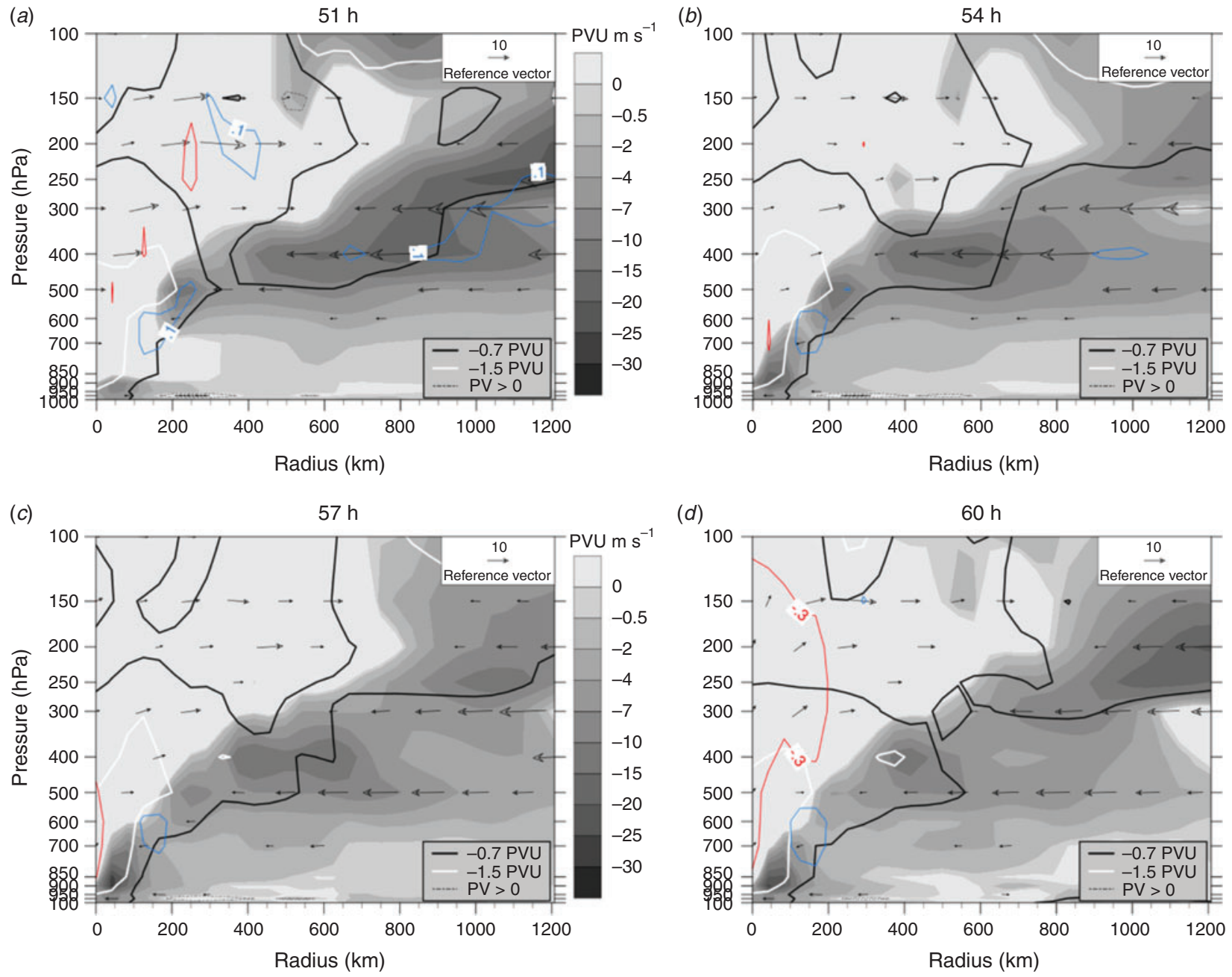

Fig. 13. As in Fig. 12 but for radius-pressure cross sections of negative values of radial potential vorticity advection $\left(-u \mathrm{PV} ; \mathrm{m} \mathrm{s}^{-1} \mathrm{PVU}\right.$, shaded $)$ at (a) 51, (b) 54, (c) 57 and (d) $60 \mathrm{~h}$ from the storm centre to 1200-km south of it. Arrows represent the radial and vertical ( $-10 \times$ omega) wind vectors. Red, blue, white and black contours as in Fig. 12.

environmental interaction. The parameters are ' $A$ ', the per cent area of air from the environment and 'PV', the per cent PV coming from the environment.

Figure 15 shows at each 0000 UTC time, the trajectories of parcels that arrived at the points scattered within the circulation at $7 \mathrm{~km}$. This level has been chosen since the merger between the PV anomaly (PVA) and the storm circulation occurs at this level (Fig. 12). The trajectories illustrated in Fig. 15 clearly demonstrate that the Oswald circulation evolved from an isolated vortex which was not interacting with its environment (upper left panel) to a vortex which was strongly interacting with its environment for the next 5 days. Note as well that there appeared to be two inflow streams: the first from the south-west and a second from the south. The interaction is quantified in Fig. 16 which shows time series of the per cent ' $A$ ' and 'PV' of air which came from the environment. The interaction commenced $\sim 23$ January, basically increased up to 26 January and then rapidly increased beyond this time (Figs 15 and 16). The heavy rain mostly coincided with this long period of interaction (Figs 2, 3, 7 and 8; Table 1); note that the heaviest rain occurred on 27 January (Section 2) when WAA and PV injection were the strongest. Interestingly, the large increase in environmental cyclonic PV $\sim 26$ January coincided with the formation of tornadoes (Table 2). The last two panels of Fig. 15 show a decrease in cyclonic PV along the trajectories reaching the cyclone from the south-west. This clearly suggest that diabatic processes are affecting the air mass that will eventually reach the cyclone centre, as PV is conserved along trajectories in the absence of diabatic processes. The trajectory approach would be an ideal framework to estimate the contribution of moist processes to the PV structure of the cyclone (as in, e.g. Rossa et al. 2000).

Figure 17 shows the horizontal (Fig. 17a) and vertical (Fig. 17b) structure of the trajectories entering the circulation at 0600 UTC 25 January. Fig. $17 b$ is a radius-mean section and shows that, as expected, much of the air present through midlevels came from low levels in the ascent regions. But there was also a large contribution from the environment as air descended 
Injection of PV from the upper trough to the hurricane vortex.

Contribution of PV from the upper levels

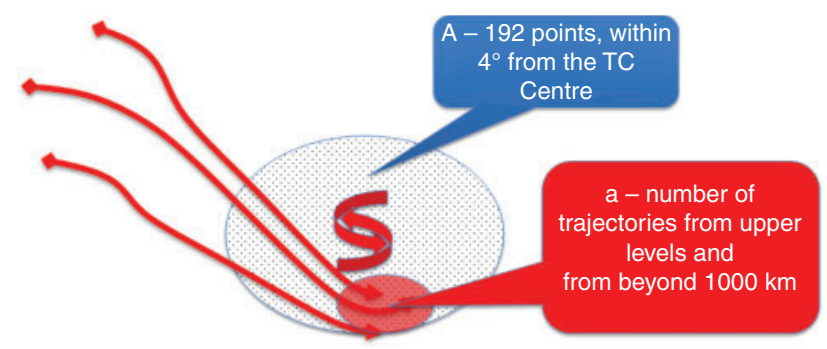

Area contribution $\%=\mathrm{a} / \mathrm{A} \quad$ Back trajectories from beyond $1000 \mathrm{~km}$

$$
P V \%=\sum_{a} P V / \sum_{A} P V
$$

Fig. 14. Schematic of the method used to calculate the contribution of air and its potential vorticity (PV) that enters the circulation from the environment. from high levels at large radii and entered the circulation through mid-levels. This is a level which is below the outflow layer (Fig. 10) but with relatively low inertial stability at that time (Fig. 11b). These structures are consistent with the previous PV analysis. With these conditions, we might expect that this region is the most favourable for inflow interactions with the environment. Also interesting to see is the very clear tilt of the vortex in the 3-D plot, from which we can expect strong ascent in the down tilt direction (i.e. to the south of the low-level circulation), consistent with the thermal advection plots (Figs 7 and 8).

\section{The vortex response to the trough forcing}

The discussion and evidence from the backward trajectories are highly suggestive that PV injection and PV advection were critical processes in the development of the major rain system that was ex-TC Oswald. How did this PV injection influence the intensity and rainfall of the system? We complement the backward trajectory approach above by analysing Hovmöller diagrams of azimuthal mean variables to investigate the mean effect of the interaction on the storm structure and intensity. We add angular momentum considerations to the PV analysis.
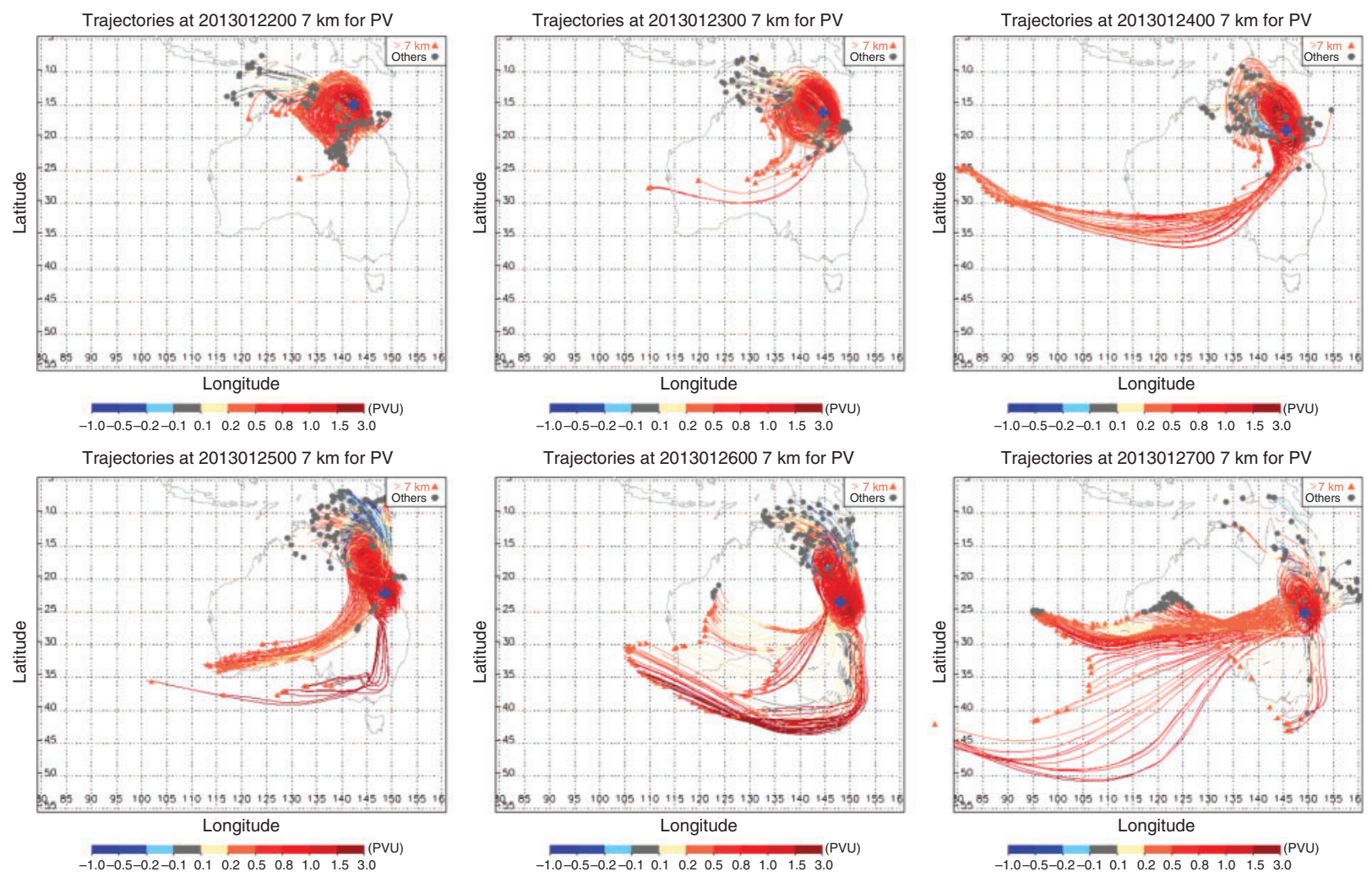

Fig. 15. HYSPLIT Lagrangian 3-day backward trajectories ending at points scattered within the Oswald circulation at $7 \mathrm{~km}$, based on 6-hourly ERA-Interim analyses. The initial time from which a backward trajectory was calculated is indicated on the corresponding panel title (from 0000 UTC 22 January to 0000 UTC 27 January). Backward trajectories are started from points surrounding the heavy rain area, indicated by the blue plus sign (+). The legend in the top-right corner indicates the symbols corresponding to air originating from above $7 \mathrm{~km}$ (orange triangle) or below $7 \mathrm{~km}$ (grey circle). The colours along trajectories indicate values of - potential vorticity (PV): red values are for cyclonic PV (negative in the southern hemisphere). 


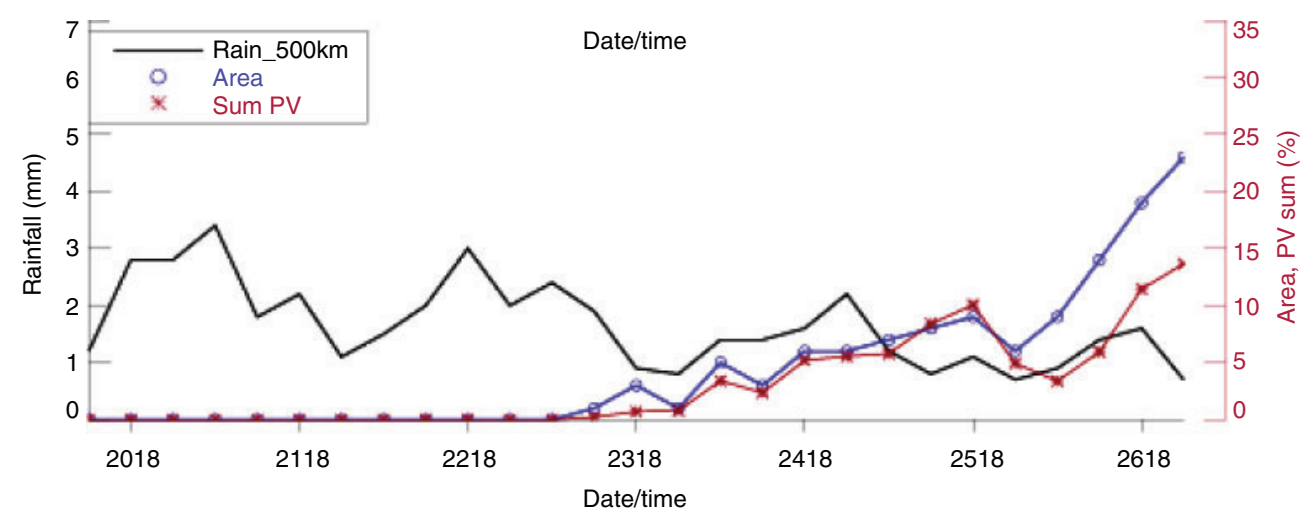

Fig. 16. Time series at 6-hourly intervals of the contributions from air and its potential vorticity (PV) that enters the Oswald circulation at $7 \mathrm{~km}$ from the environment. Also shown is the time series of accumulated rainfall over a $500-\mathrm{km}$ radius circle centred on the Oswald circulation.

The diagnostics are based on the ACCESS-R forecast used to illustrate the extratropical-tropical interaction in Fig. 12. The progression of the 400-hPa PV anomaly coming from the south of the system towards the storm centre (Fig. 18a) confirms the budget illustrated in Fig. 16 in that the PV injection in the storm centre is not only limited to after 51-h lead time as presented in Fig. 13 (which only shows what is happening in the southern sector) but also starts as early as 42 -h lead time. A complementary way to characterise the amplitude and duration of the interaction of ex-TC Oswald with the approaching trough is to compute the REAMFC (Molinari and Vollaro 1989) at $250 \mathrm{hPa}(200 \mathrm{hPa}$ is generally used for stronger storms) over a $300-600-\mathrm{km}$ radial range around the TC centre. For ex-TC Oswald, the cyclonic REAMFC (negative in the southern hemisphere) associated with the wave activity is sporadic and limited in time (Fig. 18c). Before $42 \mathrm{~h}$, cyclonic REAMFC (Fig. 18c, shaded contours) is associated with the outward transport of anticyclonic momentum by the asymmetric outflow (as depicted in E-P flux vectors, not shown), a possible important preconditioner. From lead times 42 to $54 \mathrm{~h}$ approximately, convergence of angular momentum by azimuthal cyclonic eddies (negative REAMFC) induces strong cyclonic spin-up in the TC's outflow layer which tends to further decrease the anticyclonic circulation initially present aloft the storm. At the same time, right after $42 \mathrm{~h}$, there is a shift in the location of the strongest azimuthally averaged ascent and of the radius of maximum winds at $300 \mathrm{hPa}$ (Fig. 18b). The cyclonic circulation and associated convection at $300 \mathrm{hPa}$ strengthen and contract towards the inner core of the system where they were formerly located $\sim 400-\mathrm{km}$ radius from the storm centre. During the same period from 42 to $60 \mathrm{~h}$, the azimuthal-mean tangential winds strengthen and contract at $700 \mathrm{hPa}$ (Fig. 18d). In conclusion, the storm spins up its low-level circulation in response to enhanced ascent associated with the mid-level PV injection. As the vertical velocity and deep convection increase inside the radius of maximum winds, a short period of intensification occurs in agreement with Nolan et al. (2007) and Vigh and Schubert (2009) theories. Such intensification probably occurs in answer to an increase of the azimuthally averaged heating (not shown) within the radius of maximum winds where the kinetic energy efficiency parameter is large.
As ex-TC Oswald moved south down the coast, the environment became favourable for tornado genesis as illustrated by the Rockhampton hodograph observed at 1200 UTC 24 January (Fig. 19). At that time, Rockhampton is located in the left-front quadrant of the storm; Oswald's centre is located some $400-\mathrm{km}$ north-west of Rockhampton and some $93 \mathrm{~km}(50 \mathrm{n} \mathrm{mi})$ inland (Fig. 1). This hodograph shows how the tilted vortex is associated with strong near-surface shear and a WAA wind profile (winds that turn anticyclonic with height), which are two components of the favourable shear environment for tornado formation that can promote high storm-relative helicity (Novlan and Gray, 1974, see their figure 17 for the typical hodograph of US hurricane spawned tornadoes). Novlan and Gray (1974) also showed that US hurricane tornadoes are preferably spawned in the right-front quadrant (northern hemisphere) of the storm, within $111 \mathrm{~km}(60 \mathrm{n} \mathrm{mi})$ to $463 \mathrm{~km}(250 \mathrm{n} \mathrm{mi})$ from the storm centre, and at the time when the storm centre is $93 \mathrm{~km}(50 \mathrm{n} \mathrm{mi})$ inland. Rockhampton and its surroundings were, therefore, located in a high-risk tornado area starting from 1200 UTC 24 January. It follows that Bundaberg and surroundings would have been at risk $36 \mathrm{~h}$ later, from 0000 UTC 26 January (no sounding available). Rockhampton was selected here as there were only two radiosonde stations either side of the tornado area: Rockhampton in the north and Brisbane in the south. As mentioned in Section 2, a cluster of tornadoes hit towns within Queensland's Bundaberg Region on 26 January. The anticyclonic turning wind structure observed at Rockhampton (Fig. 19) was most likely maintained as Oswald moved down to New South Wales. The URLs www.theweatherchaser.com/radar-loop/IDR661brisbane/2013-01-25-14/2013-01-26-14 and www.theweatherchaser.com/radar-loop/IDR082-gympie/2013-01-25-14/ 2013-01-26-14, accessed 8 May 2020, show Brisbane and Gympie radars covering the tornado times. The stronger echoes come from the north towards Bundaberg on 26 January. These are left-moving storm cells (moving to the left of the mean 0-6-km wind, Fig. 19). By definition, their $0-3 \mathrm{~km}$ stormrelative helicity is, therefore, greater than that of right-moving storm cells; left-moving cells in the southern hemisphere being equivalent to right-moving cells in the northern hemisphere where it is the most observed pattern for tornadoes 

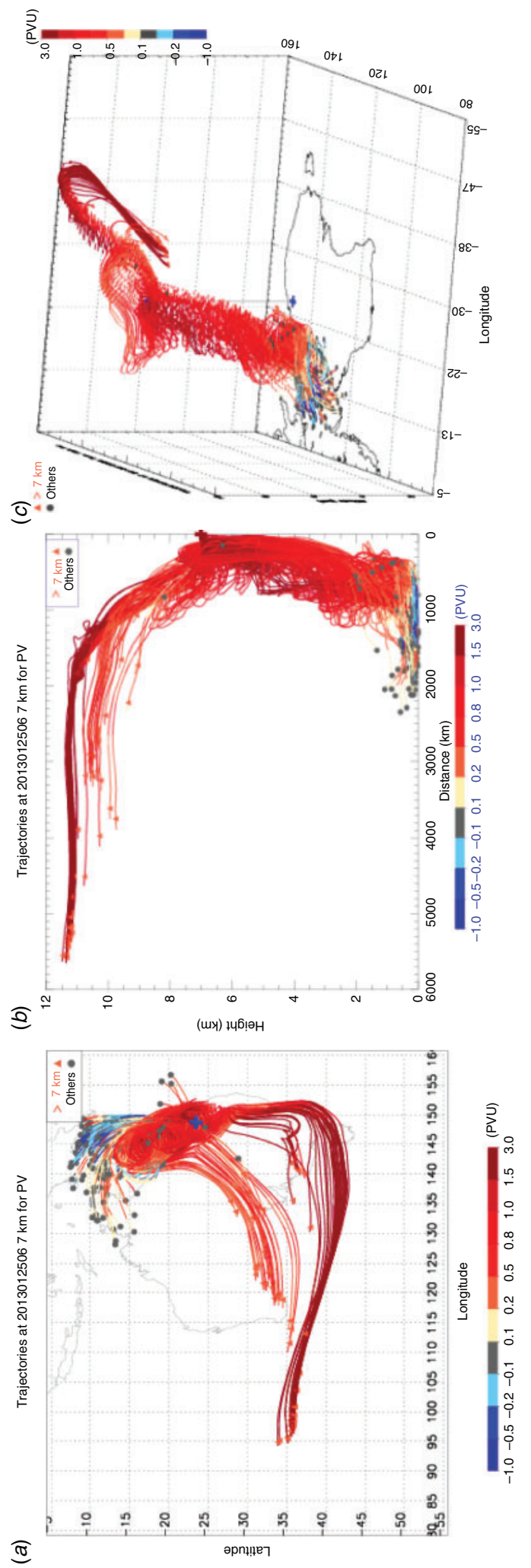

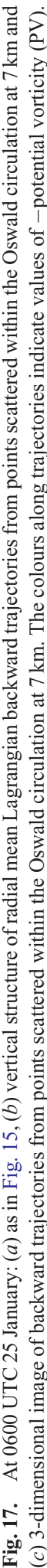

(Davies-Jones et al. 1990; Thompson et al. 2007). As a result, such storm cells are strongly conducive to tornado development as they will be more inclined to rotate and experience a large updraft-enhancing vertical pressure gradient.

\section{Summary and conclusion}

A detailed analysis of a major rain event associated with ex-TC Oswald has been presented. TC Oswald made landfall over north-east Australia as a minimal storm but as it moved southward, it strengthened even while its centre was over land and produced extreme rainfall for nearly 7 days. Tragically seven people died, and insurance estimates were $\sim \$ 1$ billion. The coastal rain amounts increased as the storm moved south and started to interact with its environment.

We demonstrate that the event was associated with an interaction between the ex-Oswald circulation and an amplifying Rossby wave, which propagated north-eastwards from high latitudes. We show that as the wave amplified and broke, a PVA extended to mid-levels moved equatorward and merged with, or axisymmetrised, the ex-Oswald circulation through mid-levels. Using backward trajectories from locations regularly scattered within a $4^{\circ}$-radius area of the ex-Oswald's mid-level circulation, we quantify the interaction via a PV injection through midlevels and illustrate that the storm transitioned from an isolated vortex into a circulation which was interacting strongly with its environment for at least 5 days. The heavy rain coincided with the commencement and maintenance of the PV injection.

We show that the PV injection is consistent with PV advection by the mean radial flow. In addition, eddy flux convergence of angular momentum became large and propagated from the environment into the storm's mid- to upper levels to intensify the circulation through this region. This was first related to outward transport of anticyclonic momentum by the asymmetric outflow at upper levels, followed by inward transport of cyclonic momentum by the asymmetric inflow from mid- to upper levels. We propose that the environmental processes described here influenced the ascent within the storm (1) via DVA and baroclinic forcing, as the mid- to upper level PVA approached the circulation, and (2) by low- to mid-level WAA. This induced (3) a direct spin-up of the vortex from the PV advection and (4) changes in the vertical structure of PV within the circulation. The circulation tilted to the south under northerly shear forcing strong ascent to the south of the low-level circulation, consistent with thermal advection plots. The environmental interaction had an impact on vortex structure changes and shear and was connected to the rainfall. It was demonstrated that the storm shortly spun up its low-level circulation in response to enhanced ascent inside the radius of maximum winds associated with the mid-level PV injection. By causing structural changes in the storm, the interaction (1) helped the storm to maintain its intensity even when the centre was well inland and under an albeit moderate $200-850-\mathrm{hPa}$ wind shear constraint and (2) possibly supported the development of tornadoes to the south-east of the storm centre under the rainband and WAA and in a favourable shear environment, increasing the damage over land.

To the critical question 'What maintained the circulation for a very long time after it made landfall?', we have provided quantitative evidence of a new paradigm for the longevity of the 
(a)

Radial PV advection (- UP V) from the south

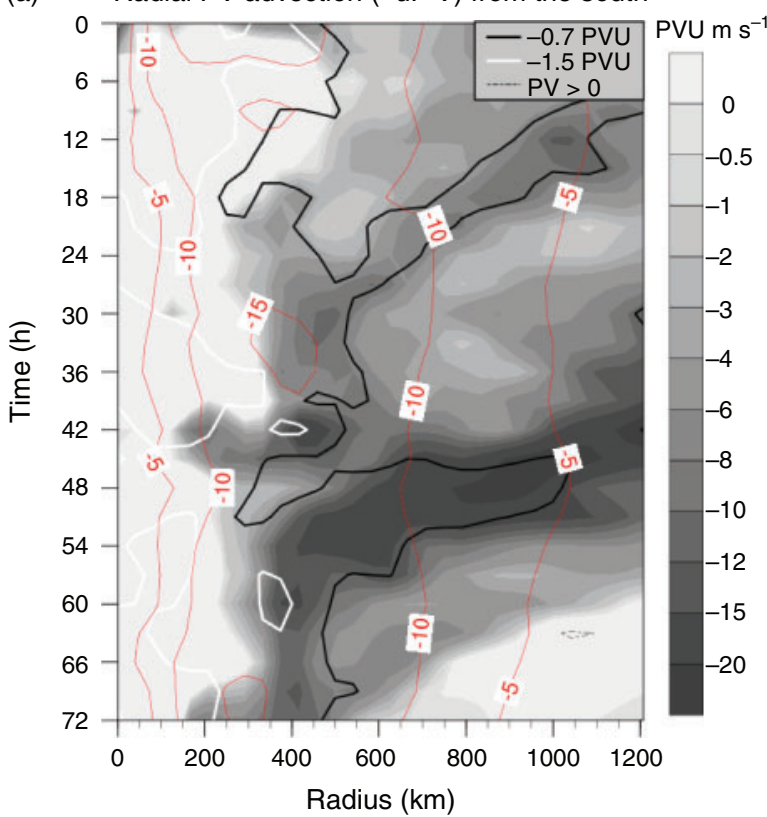

(c)

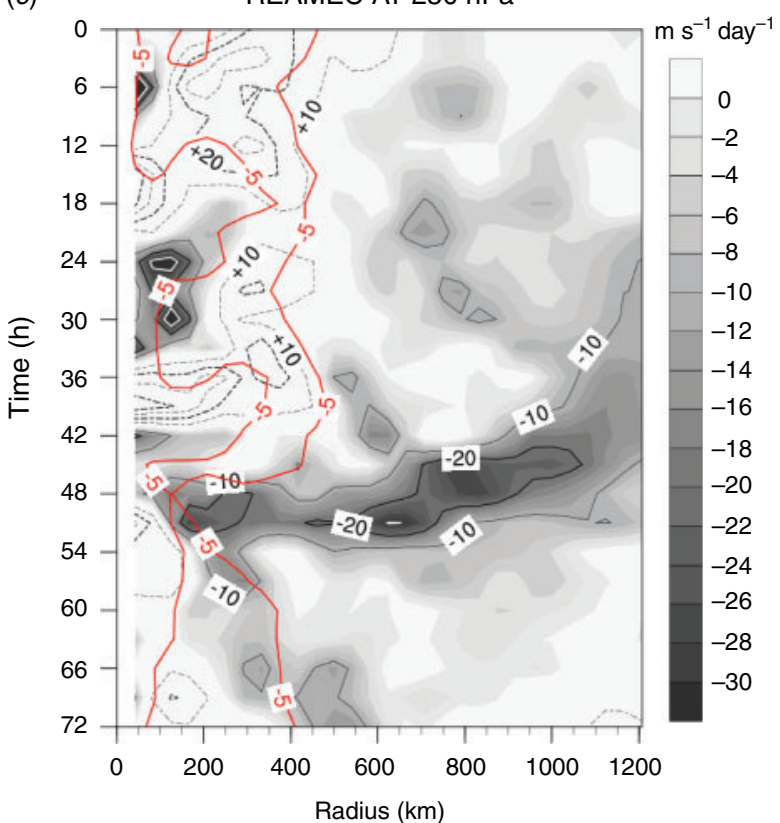

(b)

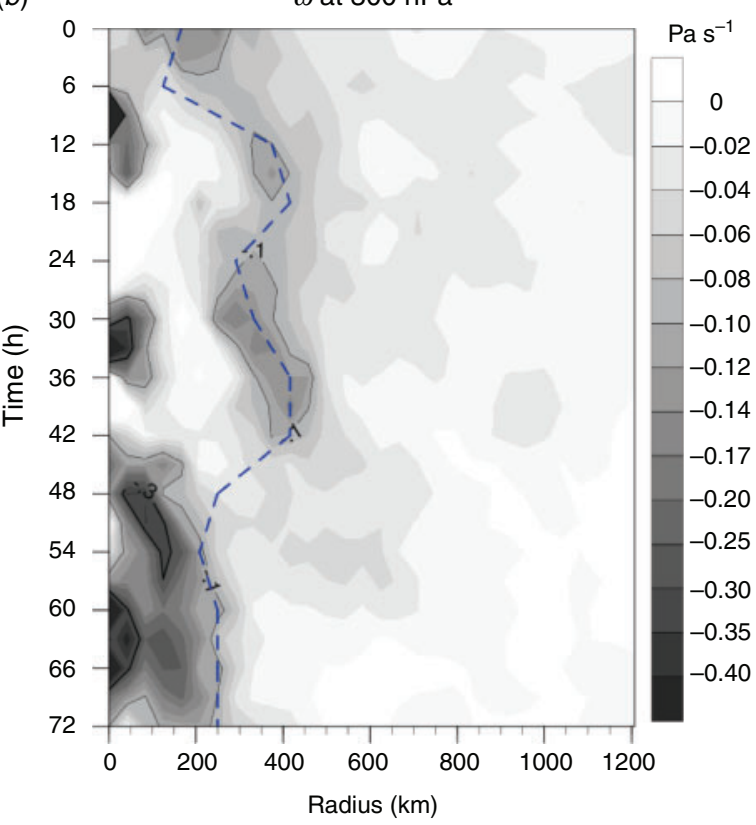

(d)

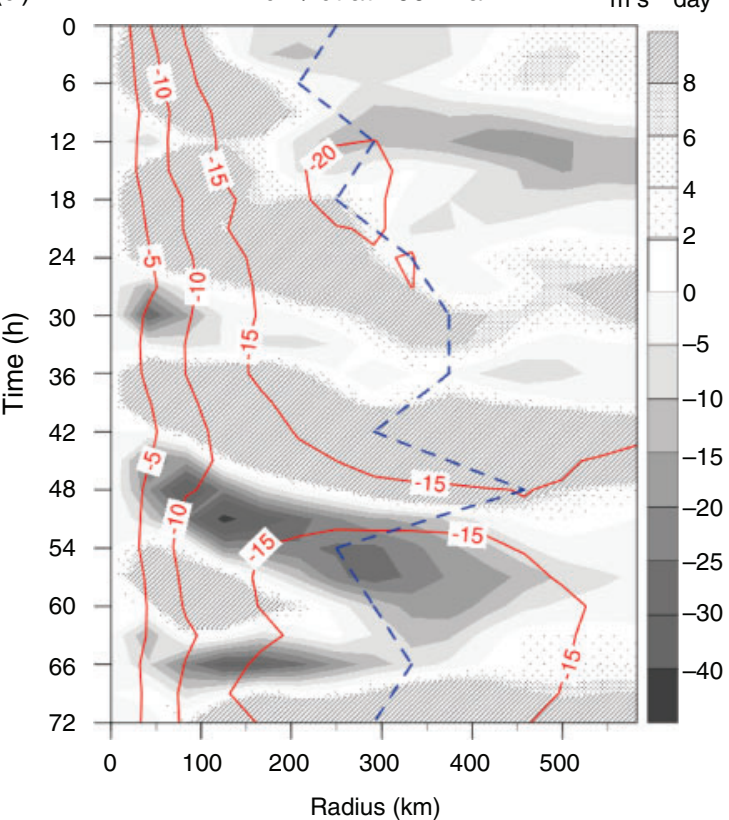

Fig. 18. Radius-time plots from the storm centre out to a $1200-\mathrm{km}(a, b, c)$ or $600-\mathrm{km}(d)$ radius in the southern direction (i.e. north-south cross sections from the storm centre) of (a) 400-hPa radial potential vorticity (PV) advection ( $-u \mathrm{PV}$; PVU m s${ }^{-1}$, shaded), (b) 300-hPa azimuthalmean vertical motion omega ( $\mathrm{Pa} \mathrm{s}^{-1}$; ascents, shaded), (c) 250-hPa relative eddy angular momentum flux convergence (REAMFC) (m s ${ }^{-1}$ day $^{-1}$; negative, i.e. cyclonic in the southern hemisphere, shaded; positive, i.e. anticyclonic in the southern hemisphere, dotted contours) and $(d)$ 700-hPa azimuthal-mean tangential wind tendency $\left(\mathrm{m} \mathrm{s}^{-1}\right.$ day $^{-1}$; negative, shaded and positive, hatched). Solid red contours show the azimuthal-mean wind $\left(\mathrm{m} \mathrm{s}^{-1}\right)$ at the corresponding pressure levels. White and black contours in $(a)$ are as in Figs 12 and 13 . The blue dashed lines in $(b, d)$ indicate the radius of maximum cyclonic (negative in the southern hemisphere) mean tangential wind at the corresponding pressure level. The azimuthal mean of a variable at a given radius $r$ is the mean of that variable over the full circle of radius $r$. REAMFC, relative eddy angular momentum flux convergence.

storm: downstream development, PV exchange with the environment, trough interaction (angular momentum budget) and quasi-geostrophic forcing of the vertical motion field.
Benefiting from a highly favourable thermodynamic and kinematic environment induced by the interaction, the slow-moving, active Oswald circulation allowed important processes to be 
(a)

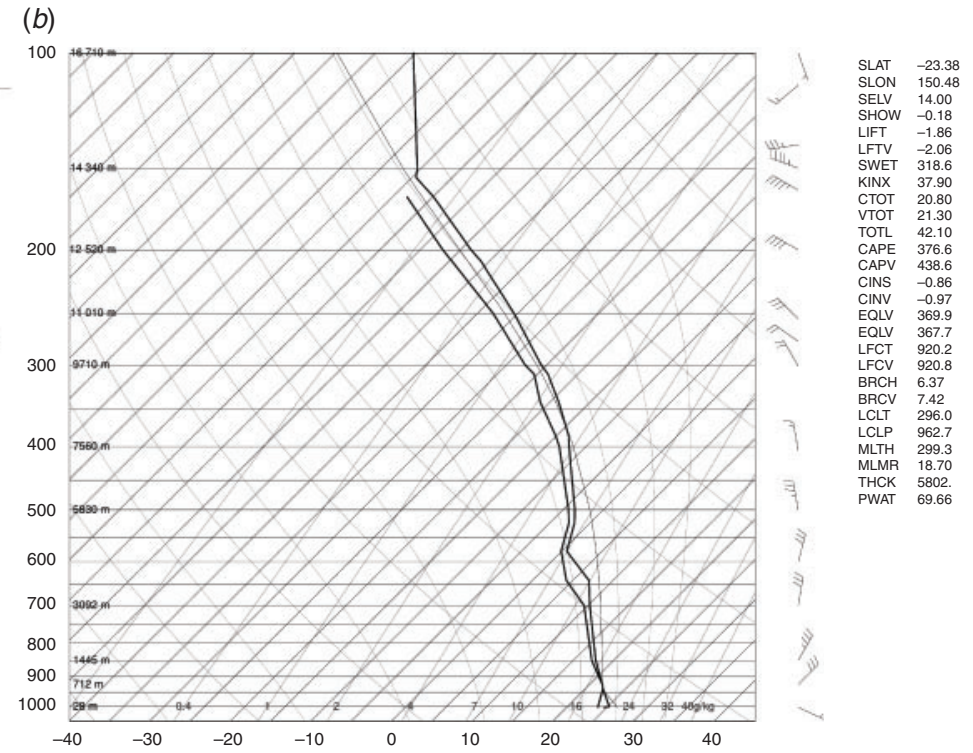

Fig. 19. Rockhampton $(a)$ hodograph and $(b)$ skew-T diagram at 1200 UTC 24 January obtained from http://weather.uwyo.edu/upperair/sounding. $\mathrm{html}$, accessed 8 May 2020. The wind axes in $(a)$ are labelled with wind speeds in $\mathrm{m} \mathrm{s}^{-1}$, and the pressure level labels are in $\mathrm{hPa}$.

active: the sustenance of long-fetch moist easterlies (as part of the downstream development) and their upslope ascent over orography, as well as WAA and DVA (as part of the quasigeostrophic forcing). Had there not been such an environmental interaction, the storm would probably have collapsed and/or have been less efficient in producing rainfall.

We hope to extend the study using numerical experimentation to better understand the contributions from topographic effects and further examine the effects from the moist processes as well as the relationship between the large increase in environmental PV and the formation of tornadoes. Highresolution convection-permitting simulations would be necessary to further investigate both storm structure changes and tornado genesis. Future investigations may also include the analysis of specific humidity along trajectories to shed light on the possible role of dry air entrainment on rainfall. We can speculate that the interaction introduces some drier air, which initially may act to reduce the rainfall, before the dynamics of the PV injection take over, that is, there may be a lag between the interaction and the heaviest rain.

\section{Acknowledgements}

This research was partially supported by the National Oceanographic Partnership Program (NOPP), the US Office of Naval Research (ONR) under Award No. N000141010139 and the France-Australia Scientific International Collaboration (FASIC) fellowship funded by two French ministries: the Ministère des Affaires Etrangères (MAE) and the Ministère de l'Enseignement Supérieur et de la Recherche (MESR). The physical insights from Dr. Chi Mai Nguyen, who tragically passed following the work on this project, were fundamental to understanding the dynamics and thermodynamics.

\section{References}

Anwender, D., Harr, P. A., and Jones, S. C. (2008). Predictability associated with the downstream impacts of the extratropical transition of tropical cyclones: case studies. Mon. Wea. Rev. 136, 3226-3247. doi:10.1175/ 2008MWR2249.1

Australian Bureau of Meteorology (2012). APS1 Upgrade of the ACCESSG Numerical Weather Prediction system. NMOC Operations Bulletin No. 93. Available at http://www.bom.gov.au/australia/charts/bulletins/ apob93.pdf [Verified 8 May 2020].

Australian Bureau of Meteorology (2013a). APS1 Upgrade of the ACCESS-R Numerical Weather Prediction System. NMOC Operations Bulletin No. 98. Available at http://www.bom.gov.au/australia/charts/ bulletins/apob98.pdf [Verified 8 May 2020].

Australian Bureau of Meteorology (2013b). Special Climate Statement $44-$ Extreme Rainfall and Flooding in Coastal Queensland and New South Wales. Available at http://www.bom.gov.au/climate/current/statements/scs44.pdf [Verified 8 May 2020].

Baek, E. H., Kim, J. H., Kug, J. S., and Lim, G. H. (2013). Favorable versus unfavorable synoptic backgrounds for indirect precipitation events ahead of tropical cyclones approaching the Korean Peninsula: a comparison of two cases. Asia-Pacific J. Atmos. Sci. doi:10.1007/S13143-013-0032-Z

Bao, X., Davidson, N. E., Yu, H., Hankinson, M. C., Sun, Z., Rikus, L. J., Liu, J., Yu, Z., and Wu, D. (2015). Diagnostics for an extreme rain event near Shanghai during the landfall of Typhoon Fitow (2013). Mon. Wea. Rev. 143, 3377-3405. doi:10.1175/MWR-D-14-00241.1

Bosart, L. F., and Lackmann, G. M. (1995). Postlandfall tropical cyclone reintensification in a weakly baroclinic environment: a case study of Hurricane David (September 1979). Mon. Wea. Rev. 123, 3268-3291. doi:10.1175/1520-0493(1995)123<3268:PTCRIA > 2.0.CO;2

Bosart, L. F., Cordeira, J. M., Galarneau, T. J., Moore, B. J., and Archambault, H. M. (2012). An analysis of multiple predecessor rain events ahead of tropical cyclones Ike and Lowell: 10-15 September 2008. Mon. Wea. Rev. 140, 1081-1107. doi:10.1175/MWR-D-11-00163.1

Callaghan, J. (2017a). A diagnostic from vertical wind profiles for detecting extreme rainfall. Trop. Cyclone Res. Rev. 6, 41-54.

Callaghan, J. (2017b). Asymmetric inner core convection leading to tropical cyclone intensification. Trop. Cyclone Res. Rev. 6, 55-66.

Callaghan, J., and Tory, K. (2014). On the use of a system-scale ascent/ descent diagnostic for short-term forecasting of tropical cyclone development, intensification and decay. Trop. Cyclone Res. Rev. 3(2), 78-90. 
Callaghan J., and Power, S. B. (2016). A vertical wind structure that leads to extreme rainfall and major flooding in southeast Australia. J. South. Hemisph. Earth Syst. Sci. 66, 380-401. doi:10.22499/3.6604.002

Chen, L. (2012). Forecasting and disasters of typhoons (in Chinese), 370pp. (China Meteorological Press.)

Colomb, A., Kriat, T., and Leroux, M. (2019). On the rapid weakening of very intense tropical cyclone Hellen (2014). Mon. Wea. Rev. 147, 2717 2737. doi:10.1175/MWR-D-18-0309.1

Cote, M. R. (2007). Predecessor rain events in advance of tropical cyclones. M.S. Thesis, Department of Earth and Atmospheric Sciences, University at Albany/SUNY, $198 \mathrm{pp}$.

Davidson, N. E., Nguyen, C. M., and Reeder, M. J. (2008). Downstream development during the rapid intensification of Hurricanes Opal and Katrina: The distant trough interaction problem. Preprints, 28th Conf. on Hurricanes and Tropical Meteorology, Orlando, FL, Amer. Meteor. Soc., 9B.4. Available online at https://ams.confex.com/ams/28Hurricanes/techprogram/paper_138060.htm [Verified 8 May 2020].

Davies-Jones, R. P., Burgess, D. W., and Foster, M. (1990). Test of helicity as a tornado forecast parameter. Preprints, 16th Conf. on Severe Local Storms, Kananaskis Park, AB, Canada, Amer. Meteor. Soc., 588-592.

Dee, D. P., Uppala, S. M., Simmons, A. J., Berrisford, P., Poli, P., Kobayashi, S., Andrae, U., Balmaseda, M. A., Balsamo, G., Bauer, P., Bechtold, P., Beljaars, A. C. M., van de Berg, L., Bidlot, J., Bormann, N., Delsol, C., Dragani, R., Fuentes, M., Geer, A. J., Haimberger, L., Healy, S. B., Hersbach, H., Hólm, E. V., Isaksen, L., Kållberg, P., Köhler, M., Matricardi, M., McNally, A. P., Monge-Sanz, B. M., Morcrette, J. -J., Park, B. -K., Peubey, C., de Rosnay, P., Tavolato, C., Thépaut, J. -N., and Vitart, F. (2011). The ERA-Interim reanalysis: configuration and performance of the data assimilation system. Q. J. R. Meteor. Soc. 137, 553597. doi: $10.1002 / \mathrm{QJ} .828$

Deng, D., Davidson, N. E., Hu, L., Tory, K. J., Hankinson, M. C., and Gao, S. (2017). Potential vorticity perspective of vortex structure changes of tropical cyclone Bilis (2006) during a heavy rain event following Landfall. Mon. Wea. Rev. 145, 1875-1895. doi:10.1175/MWR-D-16-0276.1

DeMaria, M., Kaplan, J., and Baik, J. -J. (1993). Upper-level eddy angular momentum fluxes and tropical cyclone intensity change. J. Atmos. Sci. 50, 1133-1147. doi:10.1175/1520-0469(1993)050<1133:ULEAMF $>2.0$. $\mathrm{CO} ; 2$

Dong, M., Chen, L., Li, Y., and Lu, C. (2010). Rainfall reinforcement associated with landfalling tropical cyclones. J. Atmos. Sci. 67, 35413558. doi:10.1175/2010JAS3268.1

Doswell, C. A., Brooks, H. E., and Maddox, R. A. (1996). Flash flood forecasting: an ingredients-based methodology. Wea. Forecasting 11, 560-581. doi:10.1175/1520-0434(1996)011<0560:FFFAIB $>2.0 . C O ; 2$

Draxler, R. R., and Hess, G. D. (1998). An overview of the HYSPLIT_4 modelling system for trajectories, dispersion and deposition. Aust. Met. Mag. 47, 295-308.

Emanuel, K., Callaghan, J., and Otto, P. (2008). A hypothesis for the redevelopment of warm-core cyclones over Northern Australia. Mon. Wea. Rev. 136, 3863-3872. doi:10.1175/2008MWR2409.1

Euler, C., Riemer, M., Kremer, T., and Schömer, E. (2019). Lagrangian description of air masses associated with latent heat release in tropical Storm Karl (2016) during extratropical transition. Mon. Wea. Rev. 147, 2657-2676. doi:10.1175/MWR-D-18-0422.1

Evans, C., Schumacher, R. S., and Galarneau, T. J. (2011). Sensitivity in the overland reintensification of Tropical Cyclone Erin (2007) to near soil moisture characteristics. Mon. Wea. Rev. 139, 3848-3870. doi:10.1175/ 2011MWR3593.1

Evans, C., Wood, K. M., Aberson, S. D., Archambault, H. M., Milrad, S. M., Bosart, L. F., Corbosiero, K. L., Davis, C. A., Dias Pinto, J. R., Doyle, J., Fogarty, C., Galarneau, T. J., Grams, C. M., Griffin, K. S., Gyakum, J., Hart, R. E., Kitabatake, N., Lentink, H. S., McTaggart-Cowan, R., Perrie, W., Quinting, J. F., Reynolds, C. A., Riemer, M., Ritchie, E. A., Sun, Y., and Zhang, F. (2017). The extratropical transition of tropical cyclones. Part I: Cyclone evolution and direct impacts. Mon. Wea. Rev. 145, $4317-$ 4344. doi:10.1175/MWR-D-17-0027.1

Holland, G. J. (1987). Chapter 2: Mature structure and structure change. In 'A Global View of Tropical Cyclones'. (Ed. R. L. Elsberry.) pp. 13-52. (Office of Naval Research.)

Fischer, M. S., Tang, B. H., and Corbosiero, K. L. (2017). Assessing the influence of upper tropospheric troughs on tropical cyclone intensification rates after genesis. Mon. Wea. Rev. 145, 1295-1313. doi:10.1175/ MWR-D-16-0275.1

Galarneau, T. J., Bosart, L. F., and Schumacher, R. S. (2010). Predecessor rain events ahead of tropical cyclones. Mon. Wea. Rev. 138, 3272-3297. doi: 10.1175/2010MWR3243.1

Galarneau, T. J., Davis, C. A., and Shapiro, M. A. (2013). Intensification of Hurricane Sandy (2012) through extratropical warm core seclusion. Mon. Wea. Rev. 141, 4296-4321. doi:10.1175/MWR-D-13-00181.1

Gao, S. Z., Meng, Z. Y., Zhang, F. Q., and Bosart, L. F. (2009). Observational analysis of heavy rainfall mechanisms associated with severe tropical storm Bilis (2006) after its landfall. Mon. Wea. Rev. 137, 18811897. doi:10.1175/2008MWR2669.1

Hanley, D., Molinari, J., and Keyser, D. (2001). A composite study of the interactions between tropical cyclones and upper-tropospheric troughs. Mon. Wea. Rev. 129, 2570-2584. doi:10.1175/1520-0493(2001) $129<2570$ :ACSOTI $>2.0 . \mathrm{CO} ; 2$

Harr, P. A., and Elsberry, R. L. (2000). Extratropical transition of tropical cyclones over the western North Pacific: Part I. Evolution of structural characteristics during the transition process. Mon. Wea. Rev. 128, 26132633. doi:10.1175/1520-0493(2000)128<2613:ETOTCO > 2.0.CO;2

Hartmann, D. L., Mechoso, C. R., and Yamazaki, K. (1984). Observations of wave-mean flow interaction in the Southern Hemisphere. J. Atmos. Sci. 41, 351-362. doi:10.1175/1520-0469(1984)041<0351:OOWMFI >2.0.CO;2

Holton, J. P. (1979). An Introduction to Dynamic Meteorology, 2nd Edn. International Geophysics Series, 23, 390 pp. (Academic Press.)

Hoskins, B. J., McIntyre, M. E., and Robertson, A. W. (1985). On the use and significance of isentropic potential vorticity maps. Q. J. R. Meteor. Soc. 111, 877-946. doi:10.1002/QJ.49711147002

Jones, D. A., Wang, W., and Fawcett, R. (2009). High-quality spatial climate data-sets for Australia. Aust. Meteor. Oceanogr. J. 58, 233-248. doi:10. 22499/2.5804.003

Jones, S. C., Harr, P. A., Abraham, J., Bosart, L. F., Bowyer, P. J., Evans, J. L., Hanely, D. E., Hanstrum, B. N., Hart, R. E., Lalaurette, F., Sinclair, M. R., Smith, R. K., and Thorncroft, C. (2003). The extratropical transition of tropical cyclones: forecast challenges, current understanding, and future directions. Wea. Forecasting 18, 1052-1092. doi:10. 1175/1520-0434(2003)018<1052:TETOTC > 2.0.CO;2

Kaplan, J., and DeMaria, M. (2003). Large-scale characteristics of rapidly intensifying tropical cyclones in the North Atlantic basin. Wea. Forecasting 18, 1093-1108. doi:10.1175/1520-0434(2003)018<1093: LCORIT $>2.0 . \mathrm{CO} ; 2$

Keller, J. H., Grams, C. M., Riemer, M., Archambault, H. M., Bosart, L., Doyle, J. D., Evans, J. L., Galarneau, T. J., Griffin, K., Harr, P. A., Kitabatake, N., McTaggart-Cowan, R., Pantillon, F., Quinting, J. F., Reynolds, C. A., Ritchie, E. A., Torn, R. D., and Zhang, F. (2019). The extratropical transition of tropical cyclones. Part II: Interaction with the midlatitude flow, downstream impacts, and implications for predictability. Mon. Wea. Rev. 147, 1077-1106. doi:10.1175/MWR-D-17-0329.1

Klein, P. M., Harr, P. A., and Elsberry, R. L. (2000). Extratropical transition of western North Pacific tropical cyclones: an overview and conceptual model of the transformation stage. Wea. Forecasting 15, 373-395. doi:10.1175/1520-0434(2000)015<0373:ETOWNP>2.0.CO;2

Komaromi, W. A., and Doyle, J. D. (2018). On the dynamics of tropical cyclone and trough interactions. J. Atmos. Sci. 75, 2687-2709. doi:10. 1175/JAS-D-17-0272.1 
Lee, D. K., and Choi, S. J. (2010). Observation and numerical prediction of torrential rainfall over Korea caused by Typhoon Rusa (2002). J. Geophys. Res. 115, D12105. doi:10.1029/2009JD012581

Leroux, M., Plu, M., and Roux, F. (2016). On the sensitivity of tropical cyclone intensification under upper-level trough forcing. Mon. Wea. Rev. 144, 1179-1202. doi:10.1175/MWR-D-15-0224.1

Leroux, M., Plu, M., Barbary, D., Roux, F., and Arbogast, P. (2013). Dynamical and physical processes leading to tropical cyclone intensification under upper-level trough forcing. J. Atmos. Sci. 70, 2547-2565. doi:10.1175/JAS-D-12-0293.1

Molinari, J., and Vollaro, D. (1989). External influences on hurricane intensity. Part I: Outflow layer eddy momentum fluxes. J. Atmos. Sci. 46, 1093-1105. doi:10.1175/1520-0469(1989)046<1093:EIOHIP $>2$. $0 . \mathrm{CO} ; 2$

Molinari, J., and Vollaro, D. (1990). External influences on hurricane intensity. Part II: Vertical structure and response of the hurricane vortex. J. Atmos. Sci. 47, 1902-1918. doi:10.1175/1520-0469(1990)047<1902: EIOHIP $>2.0 . \mathrm{CO} ; 2$

Molinari, J., Skubis, S., and Vollaro, D. (1995). External influences on hurricane intensity. Part III: Potential vorticity structure. J. Atmos. Sci., 52, 3593-3606.

Molinari, J., Skubis, S., Vollaro, D., Alsheimer, F., and Willoughby, H. E. (1998). Potential vorticity analysis of tropical cyclone intensification. J. Atmos. Sci., 55, 2632-2644.

Moore, B. J., Bosart, L. F., Keyser, D., and Jurewicz, M. L. (2013). Synopticscale environments of predecessor rain events occurring east of the Rocky Mountains in association with Atlantic basin tropical cyclones. Mon. Wea. Rev. 141, 1022-1047. doi:10.1175/MWR-D-12-00178.1

Nolan, D. S., Moon, Y., and Stern, D. P. (2007). Tropical cyclone intensification from asymmetric convection: energetics and efficiency. J. Atmos. Sci. 64, 3377-3405. doi:10.1175/JAS3988.1

Novlan, D. J., and Gray, W. M. (1974). Hurricane-spawned tornadoes. Mon. Wea. Rev. 102, 476-488. doi:10.1175/1520-0493(1974)102<0476: $\mathrm{HST}>2.0 . \mathrm{CO} ; 2$

Pohorsky, R., Röthlisberger, M., Grams, C. M., Riboldi, J., and Martius, O. (2019). The climatological impact of recurving North Atlantic tropical cyclones on downstream extreme precipitation events. Mon. Wea. Rev. 147, 1513-1532. doi:10.1175/MWR-D-18-0195.1

Puri, K. P., Dietachmayer, G., Steinle, P., Dix, M., Rikus, L., Logan, L., Naughton, M., Tingwell, C., Xiao, Y., Barras, V., Bermous, I., Bowen, R., Deschamps, L., Franklin, C., Fraser, J., Glowacki, T., Harris, B., Lee, J., Le, T., Roff, G., Sulaiman, A., Sims, H., Sun, X., Sun, Z., Zhu, H., Chattopadhyay, M., and Engel, C. (2013). Implementation of the initial
ACCESS numerical weather prediction system. Aust. Meteor. Oceanogr. J. 65, 265-284. doi:10.22499/2.6302.001

Quinting, J. F., Bell, M. M., Harr, P. A., and Jones, S. C. (2014). Structural characteristics of T-PARC typhoon Sinlaku during its extratropical transition. Mon. Wea. Rev. 142, 1945-1961. doi:10.1175/MWR-D-1300306.1

Ritchie, E. A., and Elsberry, R. L. (2003). Simulations of the extratropical transition of tropical cyclones: contributions by the midlatitude upperlevel trough to reintensification. Mon. Wea. Rev. 131, 2112-2128. doi:10.1175/1520-0493(2003)131<2112:SOTETO > 2.0.CO;2

Ritchie, E. A., and Elsberry, R. L. (2007). Simulations of the extratropical transition of tropical cyclones: phasing between the upper-level trough and tropical cyclones. Mon. Wea. Rev. 135, 862-876. doi:10.1175/ MWR3303.1

Rossa, A., Wernli, H., and Davies, H. C. (2000). Growth and decay of an extra-tropical cyclone's PV-tower. Meteorol. Atmos. Phys. 73, 139-156. doi:10.1007/S007030050070

Smith, R. K., Montgomery, M. T., Kilroy, G., Tang, S., and Mueller, S. K. (2015). Tropical low formation during the Australian monsoon: the events of January 2013. Aust. Meteor. Oceanogr. J. 65(3), 318-341. doi: $10.22499 / 2.6503 .003$

Srock, A. F., and Bosart, L. F. (2009). Heavy precipitation associated with southern Appalachian cold-air damming and Carolina coastal frontogenesis in advance of weak landfalling tropical storm Marco (1990). Mon. Wea. Rev. 137, 2448-2470. doi:10.1175/2009MWR2819.1

Stohl A., Forster, C., and Sodemann, H. (2008). Remote sources of water vapor forming precipitation on the Norwegian west coast at $60^{\circ} \mathrm{N}-$ a tale of hurricanes and an atmospheric river. J. Geophys. Res. 113, D05102. doi:10.1029/2007JD009006

Thompson, R. L., Mead, C. M., and Edwards, R. (2007). Effective stormrelative helicity and bulk shear in supercell thunderstorm environments. Wea. Forecasting 22, 102-115. doi:10.1175/WAF969.1

Tory, K. (2014). The turning winds with height thermal advection rainfall diagnostic: why does it work in the tropics?. Aust. Meteor. Oceanogr. J. 64(3), 231-238. doi:10.22499/2.6403.005

Vigh, J. L., and Schubert, W. H. (2009). Rapid development of the tropical cyclone warm core. J. Atmos. Sci. 66, 3335-3350. doi:10.1175/ 2009JAS3092.1

Wei, N., Li, Y., Zhang, D., Mai, Z., and Yang, S. (2016). A statistical analysis of the relationship between upper-tropospheric cold low and tropical cyclone track and intensity change over the western North Pacific. Mon. Wea. Rev. 144, 1805-1822. doi:10.1175/MWR-D-150370.1 